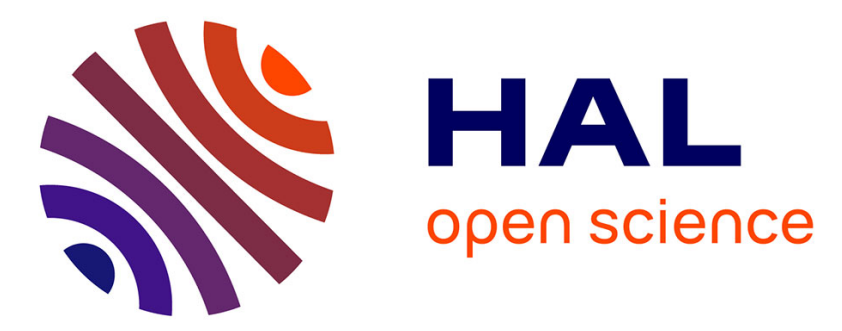

\title{
Sex and hatching order modulate the association between MHC-II diversity and fitness in early-life stages of a wild seabird
}

Maxime Pineaux, Thomas Merkling, Etienne Danchin, Scott Hatch, David Duneau, Pierrick Blanchard, Sarah Leclaire

\section{To cite this version:}

Maxime Pineaux, Thomas Merkling, Etienne Danchin, Scott Hatch, David Duneau, et al.. Sex and hatching order modulate the association between MHC-II diversity and fitness in early-life stages of a wild seabird. Molecular Ecology, 2020, 29 (17), pp.3316-3329. 10.1111/mec.15551 . hal-03367902

\section{HAL Id: hal-03367902 \\ https://hal.science/hal-03367902}

Submitted on 12 Oct 2021

HAL is a multi-disciplinary open access archive for the deposit and dissemination of scientific research documents, whether they are published or not. The documents may come from teaching and research institutions in France or abroad, or from public or private research centers.
L'archive ouverte pluridisciplinaire $\mathbf{H A L}$, est destinée au dépôt et à la diffusion de documents scientifiques de niveau recherche, publiés ou non, émanant des établissements d'enseignement et de recherche français ou étrangers, des laboratoires publics ou privés. 


\section{TITLE}

2 Sex and hatching order modulate the association between MHC-II diversity and fitness in early-life

3 stages of a wild seabird

\section{RUNNING TITLE}

$5 \quad$ MHC-II diversity and fitness in kittiwake chicks

\section{AUTHORS}

7 Maxime Pineaux ${ }^{1 \ddagger}$, Thomas Merkling ${ }^{1}$, Etienne Danchin ${ }^{1}$, Scott Hatch ${ }^{2}$, David Duneau ${ }^{1}$, Pierrick

8 Blanchard $^{1+}$, Sarah Leclaire $^{1+}$

9 1'Laboratoire Évolution \& Diversité Biologique (EDB UMR 5174), Université Fédérale de Toulouse Midi-Pyrénées, CNRS, IRD, UPS. 118 route de Narbonne, Bât. 4R1, 31062 Toulouse cedex 9 France

112 Institute for Seabird Research and Conservation, 12850 Mountain Place, Anchorage AK 99516, USA

$13{ }^{+}$co-last authors 


\section{ABSTRACT}

Genes of the major histocompatibility complex $(\mathrm{MHC})$ play a pivotal role in parasite resistance, and their allelic diversity has been associated with fitness variations in several taxa. However, studies report inconsistencies in the direction of this association, with either positive, quadratic or no association being described. These discrepancies may arise because the fitness costs and benefits of MHC-diversity differ among individuals depending on their exposure and immune responses to parasites. Here, we investigated in black-legged kittiwake (Rissa tridactyla) chicks whether associations between MHC class-II diversity and fitness vary with sex and hatching order. MHC-II diversity was positively associated with growth and tick clearance in female chicks, but not in male chicks. Our data also revealed a positive association between MHC-II diversity and survival in second-hatched female chicks (two eggs being the typical clutch size). These findings may result from condition-dependent parasite infections differentially impacting sexes in relation to hatching order. We thus suggest that it may be important to account for individual heterogeneities in traits that potentially exert selective pressures on MHC-diversity in order to properly predict MHC-fitness associations.

\section{KEYWORDS}

Divergent allele advantage; fitness; heterozygote advantage; immunity; Ixodes uriae; parasitemediated selection

\section{INTRODUCTION}

Identifying the genetic bases of fitness differences among individuals is a long-standing goal in evolutionary biology (Chapman, Nakagawa, Coltman, Slate, \& Sheldon, 2009; Ellegren \& Sheldon, 2008; Merila \& Sheldon, 1999). In this context, immune-related genes have drawn substantial attention (Bateson et al., 2016; Froeschke \& Sommer, 2005; Oliver, Telfer, \& Piertney, 2009; Sepil, Lachish, Hinks, \& Sheldon, 2013) because parasite resistance often covaries with fitness in wild populations (Asghar et al., 2015; Hamilton \& Zuk, 1982; Moller, Arriero, Lobato, \& Merino, 2009; 
Willink \& Svensson, 2017). The major histocompatibility complex (MHC) is a cluster of genes coding for cell surface proteins that are essential for the adaptive immune system. The MHC plays a critical role in modulating self/non-self discrimination and in activating immune response against parasites (Murphy \& Weaver, 2017). In past decades, several studies reported associations between MHC allelic diversity and fitness, but with some major inconsistencies. For instance, depending on the considered species or population, either maximal or intermediate MHC-diversity was found to maximize fitness (Bonneaud, Mazuc, Chastel, Westerdahl, \& Sorci, 2004; Kalbe et al., 2009; Lenz, Mueller, Trillmich, \& Wolf, 2013; Thoss, Ilmonen, Musolf, \& Penn, 2011; Wegner, Reusch, \& Kalbe, 2003).

The reported inconsistencies in the fitness consequences of MHC-diversity likely stem from the variations in the trade-off between the different functions of the MHC. The fact that each MHC protein can bind a limited set of antigens leads to the straightforward expectation that an increase in $\mathrm{MHC}$ diversity increases the number of antigens recognized, thereby providing resistance to a wider range of parasites (reviewed in Milinski, 2006). Higher MHC-diversity may also lead to more efficient immune responses during infection (Behnke \& Wahid, 1991; Doherty \& Zinkernagel, 1975; McClelland, Penn, \& Potts, 2003). However, theoretical models have shown that high MHC-diversity can also incur costs by limiting the potential for inducing an immune reaction (Nowak, Tarczyhornoch, \& Austyn, 1992; Woelfing, Traulsen, Milinski, \& Boehm, 2009; see also Migalska et al. 2019) or by increasing the potential for autoimmune disorders (Borghans \& De Boer, 2001).

Variation in the level of MHC-diversity maximizing fitness should be shaped by any selective pressure associated with changes in exposure to parasites, immune response strength or susceptibility to autoimmunity. Several studies have shown that MHC-diversity varies among species or populations according to key life-history traits. For instance, increased mean MHC-diversity has been associated with migratory behavior and female promiscuity, two traits that may increase exposure and/or reduce immune response to parasites (Gohli et al., 2013; Minias, Pikus, Whittingham, \& Dunn, 2019; 
Whittingham, Dunn, Freeman-Gallant, Taff, \& Johnson, 2018; Winternitz et al., 2013). In contrast, studies investigating interindividual variation in the fitness consequences of MHC-diversity within a population are scarce, although there is extensive evidence for interindividual variations in these potential selective pressures (i.e. exposure to parasites, immune response strength or susceptibility to autoimmunity). For instance, it has been recently hypothesized that sex differences in the effects of immunosuppressive sex hormones on the strength of immune response and on the susceptibility to autoimmunity should result in different optima of MHC diversity between males and females (Roved, Westerdahl, \& Hasselquist, 2017). Specifically, the authors argued that males should benefit from higher levels of MHC-diversity than females because sex hormones reduce immune activation in males and increase susceptibility to autoimmunity in females. Accordingly, the association between MHCdiversity and reproductive success was positive in adult males but not in adult females in great reed warblers (Acrocephalus arundinaceus) (Roved, Hansson, Tarka, Hasselquist, \& Westerdahl, 2018). This hypothesis may explain similar findings in other species (Huchard, Knapp, Wang, Raymond, \& Cowlishaw, 2010; Sauermann et al., 2001; Schaschl et al., 2012). There may be other explanations for why males benefit from higher levels of MHC-diversity than females. For instance, male-male contests increase males' risk of wounds and thus infections (Huchard et al., 2010 and references therein), and deplete males' energetic reserves, thereby possibly leading to less energy available for allocation to immune functions (Schaschl et al., 2012 and references therein). While a few other studies investigated sex-specific associations between MHC-diversity and fitness (Hablutzel et al., 2014; Jager et al., 2007; Lenz, Eizaguirre, Scharsack, Kalbe, \& Milinski, 2009), no studies have investigated whether other individual traits may modulate these associations. Sex is not the only trait modulating exposure to parasites or immune response strength. For instance, social status and personalities have been associated with infection risks by influencing frequency and duration of interactions with conspecifics (Boyer, Reale, Marmet, Pisanu, \& Chapuis, 2010; Drewe, 2010; Habig \& Archie, 2015). 
Here, we investigated whether differences in sex and hatching order are associated with variation in the fitness consequences of MHC class-Il diversity during the nestling stage in a wild population of the monogamous black-legged kittiwakes (Rissa tridactyla). In kittiwakes, female and second-hatched chicks are smaller, grow slower (Merkling et al., 2012; Vincenzi, Hatch, Mangel, \& Kitaysky, 2013; Vincenzi, Hatch, Merkling, \& Kitaysky, 2015) and suffer more from sibling aggressions (Delaunay, 2018; White, Leclaire, et al., 2010) than other chicks, suggesting that they are less competitive for food and in poorer condition. In several other species, including birds, food shortage and reduced condition have been linked to reduced immune responses via energy trade-offs (Beldomenico \& Begon, 2010; Brzek \& Konarzewski, 2007) or chronic stress (Glaser \& Kiecolt-Glaser, 2005). In addition, in kittiwakes, second-hatched chicks hatch from eggs containing increased levels of androgens compared to first-hatched chicks (Benowitz-Fredericks, Kitaysky, Welcker, \& Hatch, 2013; Gasparini et al., 2007). This may lead to reduced immune responses as these sex hormones are known to be immunosuppressive in other species (Klein \& Flanagan, 2016; Smyth, Caruso, Davies, CluttonBrock, \& Drea, 2018). Thus, females and second-hatched chicks are predicted to be immunologically disadvantaged compared to males and first-hatched chicks. Because individuals who have less efficient immune response are hypothesized to be particularly advantaged by high MHC-diversity (Roved et al., 2017), we expect, the fitness of females and second-hatched chicks to be more dependent on MHCdiversity than the fitness of males and first-hatched chicks. We thus investigated whether the association between fitness-related traits and MHC class-II diversity varied with sex and hatching order. We tested several fitness-related traits, namely survival in the nest, growth rate and tick infection during the nestling stage. Growth rate is an important component of fitness in kittiwakes because faster growing chicks are more likely to recruit as breeders (Vincenzi et al., 2015). Ticks can have strong deleterious effects on kittiwake chicks by reducing growth rate when food is scarce (McCoy, Boulinier, Schjorring, \& Michalakis, 2002), potentially leading to death in case of hyper- 
by MHC class II molecules, which present them to T lymphocytes, thereby activating an immune response that can reduce tick-feeding efficiency and eventually lead to tick detachment (Andrade, Texeira, Barral, \& Barral-Netto, 2005; Oliver et al., 2009; Owen, Nelson, \& Clayton, 2010).

\section{MATERIALS AND METHODS}

\section{Study site}

The study was conducted during the 2007-2013 and 2016-2017 breeding seasons (May-August) on a colony of black-legged kittiwakes nesting on an abandoned U.S. Air Force radar tower on Middleton Island $\left(59^{\circ} 26^{\prime} \mathrm{N}, 146^{\circ} 20^{\prime} \mathrm{W}\right)$, Gulf of Alaska. The 400 nest sites created on the upper walls of the tower can be observed from inside the building through sliding one-way mirrors and birds are individually identified using color and metal bands (Gill \& Hatch, 2002). All nest sites were checked twice daily (9:00 and 18:00) to record laying, hatching and death events. We focused on two-eggs clutches, which is the typical clutch size in this kittiwake population (range 1-3; Gill \& Hatch, 2002). There is generally a twoday interval between laying of the first and second egg, which usually results in an asynchronous hatching by a day or two (Coulson, 2011). On the day of laying, A- and B- eggs (first- and second-laid eggs, respectively) were labeled individually with a non-toxic marker. Chicks were marked on the head with similar markers for identification shortly after hatching.

\section{DNA collection and sexing}

Chicks were sexed molecularly using DNA extracted from eggshells, tissues from embryos (in case of pre-hatching death) or blood collected from the metatarsal vein (see Merkling et al., 2012 for a detailed sexing protocol). A few chicks $(n=18)$ were sexed a posteriori when they came back to the colony as adults (identified with a numbered metal ring). We used DNA extracted from a blood sample collected on adults with a syringe or capillaries from the brachial vein to determine sex using the same molecular method as for chicks (Merkling et al., 2012). The sex of a few adults $(n=4)$ was determined 
using sex-specific behavior (i.e. copulation and courtship feeding during the prelaying period; Danchin, 1991; Jodice, Lanctot, Gill, Roby, \& Hatch, 2000).

\section{Molecular analysis of major histocompatibility complex}

\section{MHC genotyping}

The DNA samples were used to amplify $258 \mathrm{bp}$ fragments ( $218 \mathrm{bp}$ excluding primers) of the exon 2 of the black-legged kittiwake MHC class-IIB. We used the MHC class-IIB specific primers (forward: 5' GCACGAGCAGGGTATTTCCA and reverse: 5' GTTCTGCCACACACTCACC) designed by Leclaire et al. (2014), which amplify at least two MHC class-IIB loci. These loci are presumed to be functional as shown by signs of positive selection, by the absence of stop codon or frame shift mutations in the translated alleles and by at least three alleles being transcribed in each of the two individuals studied (Leclaire et al., 2014). To discriminate samples after sequencing, the $5^{\prime}$ end of both forward and reverse primers included a combination of two different $8 \mathrm{bp}$ tags. The PCR amplification was performed in 20 $\mu \mathrm{l}$ mixtures containing $2 \mu \mathrm{l}$ of extracted DNA, $0.5 \mu \mathrm{M}$ of each primer, 1x AmpliTaq Gold ${ }^{\circledR} 360$ Master Mix (Applied Biosystems, Foster City (CA) USA) and $3.2 \mu \mathrm{g}$ of bovine serum albumin (Roche Diagnostics, Basel, Switzerland). The PCR program consisted of $10 \mathrm{~min}$ initial denaturation at $95^{\circ} \mathrm{C}$, followed by 30 cycles of $30 \mathrm{~s}$ denaturation at $95^{\circ} \mathrm{C}, 30 \mathrm{~s}$ annealing at $57^{\circ} \mathrm{C}$ and $1 \mathrm{~min} 30 \mathrm{~s}$ extension at $72^{\circ} \mathrm{C}$. A final elongation step was run at $72^{\circ} \mathrm{C}$ for $7 \mathrm{~min}$. Amplicons were then purified using the MinElute PCR Purification protocol (Qiagen, Hilden, Germany). Amplicons were sequenced in two runs with an Illumina MiSeq platform, using the $2 \times 300$ bp protocol (Fasteris SA, Plan-les-Ouates, Switzerland). We included PCR blank controls, as well as unused tag combinations, in the sequenced multiplex to detect and withdraw potential mistagging biases (Esling, Lejzerowicz, \& Pawlowski, 2015).

Amplicon sequences were analyzed with ampliSAS, a three-step pipeline that consists of read demultiplexing, unique sequence clustering, and erroneous sequence filtering (Sebastian, Herdegen, Migalska, \& Radwan, 2016). First, the Illumina data were filtered to remove low-quality sequences 
(sequences with Phred scores less than 50). Sequences were then clustered using the default ampliSAS parameters for Illumina sequences (substitution errors: $1 \%$, indel errors: $0.001 \%$, minimum frequency with respect to dominant: $25 \%$ ), and sequences that were potential chimeras or that had less than $3 \%$ frequency were discarded. We discarded samples with a depth inferior to 500 reads. Considering the larger set of samples analyzed in the two MiSeq runs $(n=2064$ samples, including 699 samples that were part of this study), the reproducibility of genotype between the two runs ( $n=25$ DNA samples that were split and processed in independent PCRs) was $100 \%$. After processing, we had an average ( \pm s.d.) of $4735 \pm 846$ reads per individual (range: $509-5000$ reads). We obtained 83 different MHC class-II alleles. All detected alleles were of the same length. The number of alleles per individual was $3.38 \pm$ 0.83 (mean \pm s.d.; range: $1-7$ ), suggesting the presence of at least 4 functional loci.

Chick MHC-Il diversity

Several measures of MHC-diversity have been used across studies (Lenz et al., 2013; Radwan et al., 2012; Sepil, Lachish, \& Sheldon, 2013). The most widely used proxy of MHC-diversity is the number of different MHC alleles possessed by an individual (e.g. Huchard et al., 2010; Kalbe et al., 2009; Roved et al., 2018). This measure relates to the "heterozygote advantage" (or overdominance) hypothesis. This hypothesis posits that heterozygous individuals should have a selective advantage over homozygous individuals, because they have a higher number of different MHC molecules, and thus can bind a higher number of antigens (Doherty \& Zinkernagel, 1975). Wakeland et al. (1990) later proposed the "divergent allele advantage" hypothesis, which posits that, in heterozygous individuals, those with higher degree of functional divergence between alleles should have a selective advantage because their MHC molecules can bind a broader range of antigens. Several studies on a single MHC locus have thus used the functional divergence between two alleles to estimate MHC-diversity (Pierini \& Lenz, 2018). Studies considering several MHC loci and using functional divergence to estimate MHC diversity are scarce. A few of them used the average functional divergence between all alleles and considered 
that individuals with higher mean divergence should be advantaged (Lenz, Wells, Pfeiffer, \& Sommer, 2009; Schwensow, Eberle, \& Sommer, 2010). However, the "divergent allele advantage" is expected to work in concert with the "heterozygote advantage" (Wakeland et al., 1990) and, when considering several loci, this estimate of MHC-diversity is, therefore, unlikely to be strongly correlated with the range of antigens bound by all alleles together. A few studies have thus used the degree of divergence over all loci to estimate MHC-diversity (Grieves, Gloor, Bernards, \& MacDougall-Shackleton, 2019; Huchard, Baniel, Schliehe-Diecks, \& Kappeler, 2013; Leclaire et al., 2019; Radwan et al., 2012). This measure is expected to estimate the range of antigens recognized by MHC molecules, regardless of whether a high range is due to the possession of many alleles that are somewhat divergent or to the possession of a few alleles that are very divergent. In our study, we decided, therefore, to estimate MHC-II diversity as the degree of divergence between alleles over all loci.

We used the Faith's diversity index to estimate MHC-II diversity as the degree of divergence of alleles across all loci (as in Grieves et al., 2019 and Leclaire et al., 2019). We first translated MHC-II DNA sequences into amino acid sequences, and considered DNA sequences as functionally identical if they had the same amino-acids in the peptide-binding regions (PBRs; inferred from Leclaire et al., 2014). Non-PBR sites were characterized by a low nucleotide diversity and codons with no significant excess of non-synonymous substitutions (Leclaire et al., 2014). We obtained a total of 68 functional alleles. The mean number of functional alleles per individual was $3.31 \pm 0.78$ (mean \pm s.d.; range: 1-7; supporting information Figure S1) and did not significantly vary among years (Kruskal-Wallis, $\mathrm{U}=4.89$, $\mathrm{df}=8, \mathrm{p}=0.77$; supporting information Figure S2). Then, following the approach of Schwensow et al. (2007), we described the chemical binding properties of each amino acid in the PBRs with the Sandberg's five physico-chemical descriptors (z-descriptors; Sandberg, Eriksson, Jonsson, Sjostrom, \& Wold, 1998). Following an approach adapted from Strandh et al. (2012), we used this Sandberg matrix to construct an alternative maximum-likelihood phylogenetic tree with "Rcontml" in the R package Rphylip (Revell \& Chamberlain, 2014). This tree represents clusters of functionally-similar MHC-II 
sequences (see supporting information Figure S3) and was used as a reference to calculate the functional diversity of an individual as the minimum total length of all the branches required to span its MHC-II alleles (i.e. Faith's phylogenetic diversity; Faith, 1992) with the R function "pd" in the picante R package (Kembel et al., 2010). In other words, for each additional allele, only the part of the peptidebinding characteristics that is not shared with other alleles is summed. Chick Faith's MHC-II diversity varied from 0.89 to 9.81 (mean \pm s.d.: $6.01 \pm 1.19$; supporting information Figure S4) and did not significantly vary among years (Kruskal-Wallis, $U=4.24, d f=8, p=0.83$; supporting information Figure S5).

For comparison with Faith's MHC-II diversity, we also carried out analyses on the association between fitness traits and the number of functional MHC-II alleles or the mean MHC-II divergence. We calculated the number of functional MHC-Il alleles as the number of amino acid PBR sequences per individual. To calculate mean MHC-II divergence, we used the Sandberg matrix to compute the Euclidean distance between all possible pairs of functional alleles (Lenz, Wells, et al., 2009) with the R function "distance" in the philentropy R package (Drost, 2018). Then for each individual, we calculated MHC-II divergence as the sum of Euclidean distances between each pair of alleles possessed by this individual, divided by the number of allele pairs. It was thus not possible to calculate MHC-II divergence for chicks carrying only one MHC-II allele ( $n=2$ individuals). Chick functional MHC-II divergence varied from 6.57 to 21.93 (mean \pm s.d.: $17.32 \pm 1.79$; Figure $S 6$ ) and did not significantly vary among years (Kruskal-Wallis, $\mathrm{U}=10.22, \mathrm{df}=8, \mathrm{p}=0.24$; Figure $\mathrm{S7}$ ).

\section{Chick fitness parameters}

Survival

To record disappearance and death, all nests were checked twice daily (9:00 and 18:00) throughout the season until we left the study site (August $15^{\text {th }}$ ). 
Chicks were measured every 5 days from hatching to the age of 35 days. We measured body mass to the nearest $0.1 \mathrm{~g}$ using an electronic scale, tarsus length to the nearest $0.1 \mathrm{~mm}$ with a caliper and wing length to the nearest $1 \mathrm{~mm}$ with a wing ruler. of a logistic growth curve between morphological measures and age (Merkling et al., 2012) using the grofit package in R (Kahm, Hasenbrink, Lichtenberg-Frate, Ludwig, \& Kschischo, 2010). Chick size was estimated by taking the scores of the first principal component analysis on wing and tarsus length at $0,5,10,15,20,25,30$ and 35 days together. Because such measurement necessarily excludes chicks that were not measured up to 35 days old, we also estimated growth rates over the first 10 days by calculating the slope of the linear regression between the morphological measures and age (Merkling et al., 2014; Merkling et al., 2016).

For each chick hatched in the 2008, 2009 and 2010 breeding seasons, we recorded the number of attached ticks (Ixodes uriae) every 5 days from 5 to 30 days through visual examination and palpation (Danchin, 1992). I. uriae is the only tick species known to infect kittiwakes on Middleton Island (BM Williams, personal communication). Ticks generally start to feed on 5-day-old chicks and parasitism may continue until fledging (Boulinier \& Danchin, 1996).

\section{Statistical analysis}

In all statistical analyses, eggs were excluded when their handling for other experimental purposes

251 could have affected fitness. Because our study aimed at investigating the effect of chick (or embryo) sex on MHC-II-fitness relationships, we excluded unsexed chicks (or embryos) from the analyses ( $n=$ 94 individuals). These filters, together with the fact that tick infections were checked only over 3 years, 
led to different sample sizes for each fitness parameter: 17 non-hatched embryos and 429 chicks were used for survival analyses, 680 chicks for the analyses on condition and size at hatching, 292 chicks for growth rate analyses over the first 10 days, 209 chicks for growth rate analyses over 35 days and 138 chicks for tick infection analyses.

\section{Model selection}

We used an AICc-based information-theoretic approach to test how Faith's MHC-II diversity was associated with fitness-related traits (Burnham \& Anderson, 2004; Burnham, Anderson, \& Huyvaert, 2011). For each fitness-related trait, we built a set of candidate models corresponding to biologically plausible hypotheses explaining the response variable. Each set of candidate models also included a null model (intercept only) and when a model included an interaction, we always considered an additive model (i.e. without the interaction). We selected the best models based on their $\triangle \mathrm{AICc}$ (i.e. the difference between the AICC of a given model and the AICC of the best model) by keeping every model with $\triangle \mathrm{AICc} \leq 4$. This cut-off can be considered as conservative and retains the true best model with an approximate $95 \%$ confidence (Richards, 2005). Using these best models, we computed natural model-averaged parameter estimates, standard errors and 95\% confidence intervals without shrinkage; i.e. parameter estimates of each variable were averaged using only the models with $\triangle \mathrm{AICc}$ $<4$ in which they appear (Nakagawa \& Freckleton, 2011). Model selection and averaging were conducted using the MuMIn package (Bartoń, 2018) and based on maximum likelihood estimation (see supporting information for an outline of all models). All statistical analyses were performed with $\mathrm{R}$ 3.5.2 (R Core Team, 2018).

For each fitness-related trait, we built a set of models that included Faith's MHC-II diversity, the square of Faith's MHC-II diversity, sex, hatching order and two- and three-way interactions between sex, hatching order and Faith's MHC-II diversity. We standardized continuous variables in all analyses and checked for collinearity issues. We detected a significant association between sex and 
Faith's MHC-II diversity at hatching (see results), and thus ran separate models for male and female chicks for all analyses. We included clutch identity (ID), pair ID and year as random effects in the models and checked for normal distribution of random effects using the best model in model selection. The pair ID random effect was however removed from models because associated variance estimates were virtually zero.

\section{Survival at the nest}

We tested for the effect of Faith's MHC-II diversity on chick survival at the nest using Cox proportional hazard mixed-effect models in the R package coxme (Therneau, 2018). We considered chick survival between 0 and 35 days (i.e. before fledging; Coulson \& White, 1958; Maunder \& Threlfall, 1972). Sixteen chicks younger than 35 days (mean \pm s.d. : $30.6 \pm 4.3$ days old) were still alive when we left the study site. To be confident that survivors included in analyses fledged after our departure, we excluded those sixteen chicks because chicks' likelihood to fledge is very high once they reach 35 days old (Barrett \& Runde, 1980; Merkling et al., 2014).

\section{Body condition and size at hatching and growth}

We used linear mixed models (LMMs) in the Ime4 R package (Bates, Machler, Bolker, \& Walker, 2015) to test for the effects of Faith's MHC-II diversity on body condition and size at hatching and on body mass and size growth rates. Chick size at hatching was included in the model built for body mass at hatching, which can thus be interpreted as size-adjusted body mass, or body condition (GarciaBerthou, 2001). We checked for normality and homoscedasticity of residuals using the best model in model selection.

\section{Tick infection}

We investigated the association between Faith's MHC-II diversity and three variables linked to tick infection. First, we determined whether Faith's MHC-II diversity was associated with the probability 
and the timing of first infection by ticks during the nestling stage (between 5 and 30 days old; $n=138$ chicks) by fitting Cox proportional hazard mixed-effect models in the R package coxme (Therneau, 2018). Chicks that were not infected by ticks during this period were right-censored $(n=28)$. Second, we focused on quantitative resistance by testing whether Faith's MHC-II diversity was associated with the maximum number of ticks chicks had during the nestling period $(n=110$ chicks, excluding those without ticks) using zero-truncated models with a Poisson distribution using the $g / m m T M B$ R package (Brooks et al., 2017). If models with a zero-truncated Poisson distribution were overdispersed, we compared their fit to the fit of models with zero-truncated negative binomial 1 and zero-truncated negative binomial 2 distributions. We pooled the values over 15 to " $15+$ " to reduce overdispersion (i.e. four chicks had more than 15 ticks). Finally, we determined whether Faith's MHC-II diversity was associated with the probability and the timing of tick clearance during the nestling stage ( $n=86$ chicks) by fitting Cox proportional hazard mixed-effect models in the R package coxme (Therneau, 2018). Chicks without ticks $(n=28)$ or discontinuously infected by ticks $(n=24)$ were excluded from this analysis. Chicks that still had ticks at the end of the observation period were right-censored. We removed the clutch ID random effect from models because associated variance estimates were virtually zero.

\section{Comparison of MHC measures}

To test the association between fitness-related traits and the number of functional MHC-II alleles or MHC-II divergence, we used the same statistical approach as for Faith's MHC-II diversity. MHCdivergence is theoretically not related to the number of alleles but, in our dataset, there was a negative correlation between these measures (Pearson correlation, $t=-5.67 ; r=0.21 ; p<0.001 ; n=697$, as in Roved, 2019). Including both measures into the same models leads to VIF values $>5$, indicating collinearity issues (Zuur, leno, \& Elphick, 2010). We therefore carried out separate analyses for the number of functional MHC-II alleles and MHC-II divergence. Because most chicks had 3 or 4 alleles in 
the restricted dataset used for tick analyses, we transformed the "number of MHC-II alleles" in a binary variable with number of MHC-II alleles $\leq 3$ or $\geq 4$ for analyses on ticks. The square of number of MHCII alleles and the interactions that included this variable were thus removed from the corresponding models. Full models including either Faith's MHC-II diversity, MHC-II divergence or number of MHC-II alleles were compared according to the Akaike information criterion (AICc) to explore the relative importance of these three different MHC-measures.

\section{RESULTS}

\section{Sex-difference in Faith's MHC-II diversity}

There was a significant association between sex and Faith's MHC-II diversity at hatching (t-test: $t=-$ 2.75; $\mathrm{p}=0.006 ; \mathrm{n}=680$ chicks) and at 35 days old (t-test: $\mathrm{t}=-2.10 ; \mathrm{p}=0.037 ; \mathrm{n}=209$ chicks). At hatching and at 35 days-old, male chicks were less MHC-II diverse than female chicks (mean \pm s.d.: males at hatching: $5.90 \pm 1.48$; males at 35 days old: $5.98 \pm 1.20$; females at hatching: $6.14 \pm 1.31$; and females at 35 days old: $6.30 \pm 1.15)$.

\section{Survival at the nest}

Among 430 monitored eggs, 142 chicks (33\%) died before reaching 35 days of age. In single-sex models, the interaction between Faith's MHC-II diversity and hatching order was significant only in females (estimate \pm s.e. $=-0.58 \pm 0.28,95 \% \mathrm{Cl}:-1.13,-0.04$; supporting information Tables S1, S2). Mortality significantly decreased with increasing Faith's MHC-II diversity in female B-chicks, but not in female Achicks, while we detected no significant effect of Faith's MHC-II diversity on mortality in males (Figures $1, \mathbf{5 8})$.

\section{Body condition and size at hatching}

Body condition at hatching was not significantly associated with Faith's MHC-II diversity (Tables S3, S4). Although there was a negative trend in males, size at hatching was not significantly associated 
with Faith's MHC-II diversity (females: estimate \pm s.e. $=0.01 \pm 0.06,95 \% \mathrm{Cl}:-0.10,0.12$; males: estimate \pm s.e. $=-0.10 \pm 0.05,95 \% \mathrm{Cl}:-0.20,0.01 ;$ Tables S5, S6).

\section{Growth}

In females only, body mass growth rate (females: estimate \pm s.e. $=0.26 \pm 0.09,95 \% \mathrm{Cl}: 0.08,0.43$; males: estimate \pm s.e. $=-0.001 \pm 0.08,95 \% \mathrm{Cl}:-0.15,0.15$; Tables S7, S8, Figure $2 \mathrm{~A}$ ) and body size growth rate over the first 10 days (females: estimate \pm s.e. $=0.24 \pm 0.09,95 \% \mathrm{Cl}$ : $0.06,0.42$; males: estimate \pm s.e. $=0.06 \pm 0.07,95 \% \mathrm{Cl}:-0.08,0.20$; Tables S9, S10, Figure $2 \mathrm{~B}$ ) were significantly and positively associated with Faith's MHC-II diversity. There was also a significant effect of the interaction between the square of Faith's MHC-II diversity and hatching order on body size growth rate in females (estimate \pm s.e. $=0.26 \pm 0.11,95 \% \mathrm{Cl}: 0.05,0.47$; Table S9). However, this interaction became nonsignificant after removing one A-female with high Faith's MHC-II diversity and moderate size growth rate (estimate \pm s.e. $=0.20 \pm 0.13,95 \% \mathrm{Cl}:-0.06,0.46$; Table S11). Similar results were obtained for growth rates over 35 days (Tables S12-S15; Figure S9).

\section{Tick infection}

In single-sex models, there was no significant association between Faith's MHC-II diversity and the age of first infection by ticks (females: estimate \pm s.e. $=-0.15 \pm 0.14,95 \% \mathrm{Cl}:-0.43,0.12$; males: estimate \pm s.e. $=-0.10 \pm 0.14,95 \% \mathrm{Cl}:-0.37,0.17$; Tables $\mathrm{S} 16, \mathrm{~S} 17$ ) or the maximum number of ticks (females: estimate \pm s.e. $=-0.29 \pm 0.22,95 \% \mathrm{Cl}:-0.73,0.15$; males: estimate \pm s.e. $=-0.01 \pm 0.26,95 \% \mathrm{Cl}:-0.51$, 0.51; Tables S18, S19). However, in females only, tick clearance was positively and significantly associated with Faith's MHC-II diversity (females: estimate \pm s.e. $=0.54 \pm 0.20,95 \% \mathrm{Cl}: 0.14,0.94$; males: estimate \pm s.e. $=-0.07 \pm 0.21,95 \% \mathrm{Cl}:-0.49,0.34$; Tables S20, S21). The more females were MHC-II diverse, the more likely and the faster they were to clear ticks (Figures 3, 4). There was no significant effect of any other parameter on these three response variables (Tables S16-S21).

\section{Comparison of MHC measures}


Faith's MHC-II diversity was significantly and positively correlated with both the number of functional MHC-II alleles (Pearson correlation, $t=8.90 ; r=0.32 ; p<0.001 ; n=699$ ) and MHC-II divergence (Pearson correlation, $t=2.89 ; r=0.11 ; p=0.004 ; n=697$ ). No effects of functional MHC-II allele number or mean MHC-II divergence on fitness traits were detected except for a sex-specific effect of allele number on tick infection, with females, but not males, possessing three MHC-II alleles or less being more likely to get infected than females with four MHC-II alleles or more (see supporting information for more details). There was also a weak effect of the square of MHC-II divergence on body mass growth rate, with chicks harboring intermediate MHC-II divergence growing faster than those with low or high MHC-II divergence (see supporting information for more details). For fitness traits associated with Faith's MHC-II diversity, full models including Faith's MHC-II diversity had lower AICc than similar models including MHC-II divergence or MHC-II allele number (Table S22). This suggests that Faith's MHC-II diversity is a better predictor of these different fitness traits than MHC-II divergence or the number of MHC-II alleles in kittiwake chicks.

\section{DISCUSSION}

Although fitness advantages have been associated with different levels of MHC-II diversity in a wide range of species and populations (Bonneaud et al., 2004; Brouwer et al., 2010; Lenz et al., 2013; Thoss et al., 2011; Wegner et al., 2003), only a handful of studies have investigated the possibility that individuals within a population might benefit from different levels of MHC-II diversity. Yet, individuals can differ greatly in exposure and immune responses to parasites, leading to the expectation that they might not benefit from MHC-II diversity the same way. In this study, we investigated whether, in kittiwake chicks, MHC-Il-fitness associations depended upon sex and hatching order, two factors expected to modulate exposure and immune response to parasites. As expected, we detected positive associations between MHC-II diversity and female chick survival, but only in second-hatched female chicks. In contrast, no association between MHC-II diversity and survival was detected in male chicks. 
High MHC-II diversity was also associated with faster growth and tick clearance in female chicks only. Our results suggest, therefore, that female chicks, especially those hatched in second position, benefit from maximal levels of MHC-II diversity while male chicks do not.

Several underlying mechanisms may explain the sex- and hatching rank-dependent effects of MHC-II diversity on fitness in kittiwake chicks. Because high MHC-II diversity provides resistance to a wider range of parasites and is associated with more efficient immune response, the fitness benefits associated with high MHC-II diversity in female chicks, particularly when hatched in second position, might be explained by weaker immune responses and/or higher exposure to parasites compared to males and A-chicks. Decreased immune response may result from higher levels of immunosuppressive sex hormones, such as androgens (Klein \& Flanagan, 2016). Although higher levels of androgens have been found in the yolk of B-eggs compared to A-eggs in kittiwakes (Benowitz-Fredericks et al., 2013; Gasparini et al., 2007), sex-differences in circulating levels of androgens have not been investigated in kittiwake chicks. However, female chicks have been found to have higher levels of androgens than male chicks in several other species (Fargallo, Martinez-Padilla, Toledano-Diaz, Santiago-Moreno, \& Davila, 2007 and references therein). Non-exclusively, weaker immune responses might also result from a trade-off between immunity and other competing functions that require metabolic resources (Zuk \& Stoehr, 2002). In kittiwakes, female- and B-chicks are smaller (Merkling et al., 2012), in poorer condition (this study; see supporting information Tables S3-S4, S23, S24; Figure S10) and suffer more from sibling aggression than other chicks (Delaunay, 2018; White, Leclaire, et al., 2010) suggesting that they might be less competitive for food, and thus have a lower amount of resources to allocate to immune functions (Beldomenico \& Begon, 2010; Beldomenico et al., 2008). Interestingly, when restricting our MHC-II-fitness analyses to broods where one egg did not hatch, thereby excluding the role of competition and aggression between siblings in driving MHC-II-fitness associations, we did not find any significant effect of MHC-II diversity on survival in female B-chicks ( $n=49$ females) or on growth rate ( $n=34$ females) or tick clearance ( $n=14$ females) in female chicks (supporting information 
Tables S25-S28). Although these results must be taken with caution because of the reduced sample size, they suggest that sibling interactions are a potential driver of sex- and rank-specific effects of MHC-II diversity on fitness in this species.

A surprising finding of our study was that female chicks had, on average, a higher MHC-II diversity than male chicks at hatching (mean \pm s.d.: $6.14 \pm 1.31$ vs. $5.90 \pm 1.48$ ). Yet, females and males should exhibit the same level of MHC-diversity as they share the genetic architecture of the MHC (i.e. MHC genes are located on autosomes; Murphy \& Weaver, 2017). Sex-difference in mean MHCdiversity has already been reported in humans, rats and mice, with increased MHC-diversity in newborn males compared to newborn females (Dorak, Lawson, Machulla, Mills, \& Burnett, 2002, and references therein). Proposed mechanisms include selective fertilization, egg resorption and embryo loss (Dorak et al., 2002). Selective fertilization and embryo loss have been associated with both the degree of MHC-similarity between parents (Lenz, Hafer, Samonte, Yeates, \& Milinski, 2018; Ober, Hyslop, Elias, Weitkamp, \& Hauck, 1998; Wedekind, Chapuisat, Macas, \& Rulicke, 1996; Zhu, Wan, Zhang, \& Fang, 2019) and with the sex of the embryo (or the sex chromosome of the gametes; Navara, 2018). However, whether they can be affected by these two parameters in interaction remains largely unknown. In our dataset, female hatchlings were still more MHC-II diverse than males when we considered only clutches with no egg loss (mean \pm s.d.: $6.20 \pm 1.12$ vs $5.93 \pm 1.15$; t-test: $t=-2.55 ; p=$ $0.01 ; n=448$ chicks), suggesting that the sex-difference in hatchlings MHC-II diversity is not triggered by a sex-specific effect of MHC-II diversity on post-laying embryo mortality. Regardless of the underlying mechanism, MHC-II-similar parents, that are more likely to produce chicks with low MHCII diversity (Setchell, Abbott, Gonzalez, \& Knapp, 2013), might benefit from avoiding the fitness costs associated with the production of low MHC-II diverse daughters.

While our results are consistent with a direct effect of MHC-II on fitness-related traits, some methodological limitations and alternative explanations must be acknowledged. First, we amplified 
exon 2 of the MHC-II because it codes for the majority of amino acids that form the peptide-binding groove in model species like humans (Brown et al., 1993; Saper, Bjorkman, \& Wiley, 1991) and because it has been the focus of most MHC research in non-model avian species (Minias, Pikus, Whittingham, \& Dunn, 2018). However, both exon 2 and exon 3 encode the peptide binding grooves on MHC-II molecules. Second, we cannot rule out the possibility that variation at other genes may partly explain our results. For instance, MHC-II alleles might be in linkage disequilibrium with other MHC genes (e.g. MHC class I genes), owing to the compact architecture of the avian MHC (Hess \& Edwards, 2002). Third, our results may possibly be explained by a broader effect of inbreeding on fitness, as variations at MHC genes can be correlated with genome-wide genetic variation depending on the life history, the dispersal ability and the breeding system of the study species (Sommer, 2005). Several studies reported sex-specific effects of inbreeding on fitness related traits (Billing et al., 2012; T. Coulson, Albon, Slate, \& Pemberton, 1999; Rioux-Paquette, Festa-Bianchet, \& Coltman, 2011). In hihis (Notiomystis cincta), the loss of inbred female embryos at a very early stage was proposed to explain increased heterozygosity in females later in the development (Brekke, Bennett, Wang, Pettorelli, \& Ewen, 2010). When testing for an association between MHC-II diversity and an estimate of genomewide diversity (i.e. standardized heterozygosity; Coltman, Pilkington, Smith, \& Pemberton, 1999) in a collection of 614 adults for which we had both MHC-II and microsatellite data (nine microsatellite loci; see Pineaux et al., 2019 for details), we found however no significant correlation (Pearson correlation: $t=0.27 ; r=0.01 ; p=0.79 ;$ supporting information Figure S11). In future, these potential effects on fitness could be disentangled by studies including multiple MHC genes and other immune genes alongside a better measure of overall inbreeding status.

This study underscores the importance of considering traits that are expected to shape an individual's exposure and immune responses to parasites when predicting the association between MHC-diversity and fitness. Sex-specific effects of MHC-diversity on fitness have been mostly studied in polygynous species, with a positive association between MHC-diversity and survival or reproductive 
success found in adult males (Huchard et al., 2010; Roved et al., 2018; Sauermann et al., 2001; Schaschl et al., 2012). Here, we provide evidence for sex-specific associations between MHC-II diversity and fitness in the early life of a monogamous species, thus calling for further research in species or populations with differing life-history strategies. A recent study in adult Leach's storm-petrels (Oceanodroma leucorhoa), a monogamous seabird, found a positive association between MHCdiversity and reproductive success in adult females but not in males (Hoover et al., 2018). The underlying explanation was that males avoided low MHC-diverse females during mate choice but it was unclear whether reduced reproductive success of low MHC-diverse females also partly resulted from a direct, detrimental effect of reduced female quality on offspring viability. For instance, female petrels may be more likely to suffer from sexually transmitted infections than males, as shown in kittiwakes (Van Dongen et al., 2019; White, Mirleau, et al., 2010), thereby explaining sex-specific effects of MHC-diversity on fitness. Future investigations of sex-specific associations between MHC-II diversity and post-fledging survival or reproductive success in kittiwakes represent an interesting avenue to explore whether the benefits of high MHC-II diversity found in female chicks persist in adult females. Importantly, ignoring early-life stages may yield only a partial picture of how MHC affects fitness if selection removes the less fit genotypes early in life, leaving only relatively high-quality individuals that survived long enough to be sampled. Such biased picture may in turn lead to a misunderstanding of the evolution of reproductive strategies.

\section{ACKNOWLEDGEMENTS}

We are grateful to the Middleton fieldworkers who collected data for this study. We also thank the undergraduate students who helped with chick sexing, U. Suescun for her advices during genetic analyses, J. B. Ferdy for statistical advices, E. Huchard, J. White and F. Helfenstein for critical comments on earlier version of the manuscript and three anonymous reviewers and subject editor J. Pemberton 
approval of the U.S. Geological Survey Alaska Science Center, the University of Alaska Institutional

Animal Care and Use Committees, and the Institut Paul-Emile Victor Ethical Committee, in accordance

496

497

498

499

500

501

with United States laws and under permits from the U.S. Fish and Wildlife Service and the State of Alaska. Any use of trade names is for descriptive purposes only and does not imply endorsement by the U.S. Government. Fieldwork was supported by a grant from the Institut Polaire Français Paul-Emile Victor (IPEV "Programme 1162 SexCoMonArc") to S.L. and E.D. This work originated in the laboratory "Evolution et Diversité Biologique" (EDB) and was supported by the French Laboratory of Excellence Project "TULIP" (ANR-10-LABX-41; ANR-11-IDEX-0002-02), and the Agence Nationale de la Recherche Française (ANR grant "BactOdo", no. ANR-13-PDOC-0002 to S.L.). M.P. was supported by a French doctoral scholarship. The authors declare no conflict of interest.

\section{REFERENCES}

Andrade, B. B., Texeira, C. R., Barral, A., \& Barral-Netto, M. (2005). Haematophagous arthropod saliva and host defense system: a tale of tear and blood. Anais Da Academia Brasileira De Ciencias, 77(4), 665-693. doi:10.1590/s0001-37652005000400008

Asghar, M., Hasselquist, D., Hansson, B., Zehtindjiev, P., Westerdahl, H., \& Bensch, S. (2015). Hidden costs of infection: Chronic malaria accelerates telomere degradation and senescence in wild birds. Science, 347(6220), 436-438. doi:10.1126/science.1261121

Barrett, R. T., \& Runde, O. J. (1980). Growth and survival of nestling kittiwakes Rissa tridactyla in Norway. Ornis Scandinavica, 11(3), 228-235. doi:10.2307/3676128

Bartoń, K. (2018). MuMIn: Multi-Model Inference. R package version 1.42.1.

Bates, D., Machler, M., Bolker, B. M., \& Walker, S. C. (2015). Fitting linear mixed-effects models using Ime4. Journal of Statistical Software, 67(1), 1-48.

Bateson, Z. W., Hammerly, S. C., Johnson, J. A., Morrow, M. E., Whittingham, L. A., \& Dunn, P. O. (2016). Specific alleles at immune genes, rather than genome-wide heterozygosity, are related to immunity and survival in the critically endangered Attwater's prairie-chicken. Molecular Ecology, 25(19), 4730-4744. doi:10.1111/mec.13793

Behnke, J. M., \& Wahid, F. N. (1991). Immunological relationships during primary infection with Heligmosomoides polygyrus (nematospiroides, Dubius) - $\mathrm{H}-2$ linked genes determine worm survival. Parasitology, 103, 157-164. doi:10.1017/s0031182000059400

Beldomenico, P. M., \& Begon, M. (2010). Disease spread, susceptibility and infection intensity: vicious circles? Trends in Ecology \& Evolution, 25(1), 21-27. doi:10.1016/j.tree.2009.06.015

Beldomenico, P. M., Telfer, S., Gebert, S., Lukomski, L., Bennett, M., \& Begon, M. (2008). Poor condition and infection: a vicious circle in natural populations. Proceedings of the Royal Society BBiological Sciences, 275(1644), 1753-1759. doi:10.1098/rspb.2008.0147

Benowitz-Fredericks, Z. M., Kitaysky, A. S., Welcker, J., \& Hatch, S. A. (2013). Effects of food availability on yolk androgen deposition in the black-legged kittiwake (Rissa tridactyla), a seabird with facultative brood reduction. Plos One, 8(5), 8. doi:10.1371/journal.pone.0062949 
Billing, A. M., Lee, A. M., Skjelseth, S., Borg, A. A., Hale, M. C., Slate, J., . . Jensen, H. (2012). Evidence of inbreeding depression but not inbreeding avoidance in a natural house sparrow population. Molecular Ecology, 21(6), 1487-1499. doi:10.1111/j.1365-294X.2012.05490.x

Bonneaud, C., Mazuc, J., Chastel, O., Westerdahl, H., \& Sorci, G. (2004). Terminal investment induced by immune challenge and fitness traits associated with major histocompatibility complex in the house sparrow. Evolution, 58(12), 2823-2830.

Borghans, J. A. M., \& De Boer, R. J. (2001). Diversity in the immune system. In L. A. S. I. R. Cohen (Ed.), Design principles for the immune system and other distributed autonomous systems (pp. 161-184). New York: NY: Oxford University Press.

Boulinier, T., \& Danchin, E. (1996). Population trends in Kittiwake Rissa tridactyla colonies in relation to tick infestation. Ibis, 138(2), 326-334. doi:10.1111/j.1474-919X.1996.tb04345.x

Boyer, N., Reale, D., Marmet, J., Pisanu, B., \& Chapuis, J. L. (2010). Personality, space use and tick load in an intrdfoduced population of Siberian chipmunks Tamias sibiricus. Journal of Animal Ecology, 79(3), 538-547. doi:10.1111/j.1365-2656.2010.01659.x

Brekke, P., Bennett, P. M., Wang, J. L., Pettorelli, N., \& Ewen, J. G. (2010). Sensitive males: inbreeding depression in an endangered bird. Proceedings of the Royal Society B-Biological Sciences, 277(1700), 3677-3684. doi:10.1098/rspb.2010.1144

Brooks, M. E., Kristensen, K., van Benthem, K. J., Magnusson, A., Berg, C. W., Nielsen, A., . . Bolker, B. M. (2017). glmmTMB balances speed and flexibility among packages for zero-inflated generalized linear mixed modeling. $R$ Journal, 9(2), 378-400.

Brouwer, L., Barr, I., van de Pol, M., Burke, T., Komdeur, J., \& Richardson, D. S. (2010). MHCdependent survival in a wild population: evidence for hidden genetic benefits gained through extrapair fertilizations. Molecular Ecology, 19(16), 3444-3455. doi:10.1111/j.1365-294X.2010.04750.x

Brown, J. H., Jardetzky, T. S., Gorga, J. C., Stern, L. J., Urban, R. G., Strominger, J. L., \& Wiley, D. C. (1993). 3-dimensional structure of the human class-II histocompatibility antigen HLA-DR1. Nature, 364(6432), 33-39. doi:10.1038/364033a0

Brzek, P., \& Konarzewski, M. (2007). Relationship between avian growth rate and immune response depends on food availability. Journal of Experimental Biology, 210(13), 2361-2367. doi:10.1242/jeb.003517

Burnham, K. P., \& Anderson, D. R. (2004). Multimodel inference - understanding AIC and BIC in model selection. Sociological Methods \& Research, 33(2), 261-304. doi:10.1177/0049124104268644

Burnham, K. P., Anderson, D. R., \& Huyvaert, K. P. (2011). AlC model selection and multimodel inference in behavioral ecology: some background, observations, and comparisons. Behavioral Ecology and Sociobiology, 65(1), 23-35. doi:10.1007/s00265-010-1029-6

Chapman, J. R., Nakagawa, S., Coltman, D. W., Slate, J., \& Sheldon, B. C. (2009). A quantitative review of heterozygosity-fitness correlations in animal populations. Molecular Ecology, 18(13), 27462765. doi:10.1111/j.1365-294X.2009.04247.x

Chastel, C., Monnat, J. Y., Lelay, G., \& Balouet, G. (1987). Infestation and hyperinfestation of kittiwake, Rissa tridactyla L., by ticks (Ixodes (C.) uriae, Ornithodoros (A.) maritimus) infected by arboviruses; pathological effects. Annales De Parasitologie Humaine Et Comparee, 62(5), 492-504. doi:10.1051/parasite/1987625492

Coltman, D. W., Pilkington, J. G., Smith, J. A., \& Pemberton, J. M. (1999). Parasite-mediated selection against inbred Soay sheep in a free-living, island population. Evolution, 53(4), 1259-1267. doi:10.2307/2640828

Coulson, J. C. (2011). The Kittiwake. London: T. \& A.D. Poyser.

Coulson, J. C., \& White, E. (1958). Observations on the breeding of the kittiwake. Bird study, 5(2), 74-83. doi:10.1080/00063655809475905

Coulson, T., Albon, S., Slate, J., \& Pemberton, J. (1999). Microsatellite loci reveal sexdependent responses to inbreeding and outbreeding in red deer calves. Evolution, 53(6), 1951-1960. doi:10.2307/2640453 
Danchin, E. (1991). Social displays of the kittiwake Rissa tridactyla. Bird Behavior, 9(1-2), 69-80.

Danchin, E. (1992). The incidence of the tick parasite Ixodes uriae in kittiwake Rissa tridactyla colonies in relation to the age of the colony, and a mechanism of infecting new colonies. Ibis, 134(2), 134-141. doi:10.1111/j.1474-919X.1992.tb08390.x

Delaunay, A. (2018). Sibling competition in a facultative siblicide species, the black-legged kittiwake (Rissa tridactyla): which role for the parents? (Master). Toulouse III - Paul Sabatier,

Doherty, P. C., \& Zinkernagel, R. M. (1975). Enhanced immunological surveillance in mice heterozygous at $\mathrm{H}-2$ gene complex. Nature, 256(5512), 50-52. doi:10.1038/256050a0

Dorak, M. T., Lawson, T., Machulla, H. K. G., Mills, K. I., \& Burnett, A. K. (2002). Increased heterozygosity for MHC class II lineages in newborn males. Genes and Immunity, 3(5), 263-269. doi:10.1038/sj.gene.6363862

Drewe, J. A. (2010). Who infects whom? Social networks and tuberculosis transmission in wild meerkats. Proceedings of the Royal Society B-Biological Sciences, 277(1681), 633-642. doi:10.1098/rspb.2009.1775

Drost, H. G. (2018). Philentropy: information theory and distance quantification with R. Journal of Open Source Software, 3(26). doi:doi:10.21105/joss.00765

Ellegren, H., \& Sheldon, B. C. (2008). Genetic basis of fitness differences in natural populations. Nature, 452(7184), 169-175. doi:10.1038/nature06737

Esling, P., Lejzerowicz, F., \& Pawlowski, J. (2015). Accurate multiplexing and filtering for highthroughput amplicon-sequencing. Nucleic Acids Research, 43(5), 2513-2524. doi:10.1093/nar/gkv107 Faith, D. P. (1992). Conservation evaluation and phylogenetic diversity. Biological Conservation, 61(1), 1-10. doi:10.1016/0006-3207(92)91201-3

Fargallo, J. A., Martinez-Padilla, J., Toledano-Diaz, A., Santiago-Moreno, J., \& Davila, J. A. (2007). Sex and testosterone effects on growth, immunity and melanin coloration of nestling Eurasian kestrels. Journal of Animal Ecology, 76(1), 201-209. doi:10.1111/j.1365-2656.2006.01193.x

Froeschke, G., \& Sommer, S. (2005). MHC class II DRB variability and parasite load in the striped mouse (Rhabdomys pumilio) in the southern Kalahari. Molecular Biology and Evolution, 22(5), 1254-1259. doi:10.1093/molbev/msi112

Garcia-Berthou, E. (2001). On the misuse of residuals in ecology: testing regression residuals vs. the analysis of covariance. Journal of Animal Ecology, 70(4), 708-711. doi:10.1046/j.13652656.2001.00524.x

Gasparini, J., Boulinier, T., Gill, V. A., Gil, D., Hatch, S. A., \& Roulin, A. (2007). Food availability affects the maternal transfer of androgens and antibodies into eggs of a colonial seabird. Journal of Evolutionary Biology, 20(3), 874-880.

Gill, V. A., \& Hatch, S. A. (2002). Components of productivity in black-legged kittiwakes Rissa tridactyla: response to supplemental feeding. Journal of Avian Biology, 33(2), 113-126.

Glaser, R., \& Kiecolt-Glaser, J. K. (2005). Science and society - Stress-induced immune dysfunction: implications for health. Nature Reviews Immunology, 5(3), 243-251. doi:10.1038/nri1571

Gohli, J., Anmarkrud, J. A., Johnsen, A., Kleven, O., Borge, T., \& Lifjeld, J. T. (2013). Female promiscuity is positively associated with neutral and selected genetic diversity in passerine birds. Evolution, 67(5), 1406-1419. doi:10.1111/evo.12045

Grieves, L. A., Gloor, G. B., Bernards, M. A., \& MacDougall-Shackleton, E. A. (2019). Songbirds show odour-based discrimination of similarity and diversity at the major histocompatibility complex. Animal Behaviour, 158, 131-138. doi:10.1016/j.anbehav.2019.10.005

Habig, B., \& Archie, E. A. (2015). Social status, immune response and parasitism in males: a meta-analysis. Philosophical Transactions of the Royal Society B-Biological Sciences, 370(1669), 17. doi:10.1098/rstb.2014.0109

Hablutzel, P. I., Vanhove, M. P. M., Gregoir, A. F., Hellemans, B., Volckaert, F. A. M., \& Raeymaekers, J. A. M. (2014). Intermediate number of major histocompatibility complex class IIB 
length variants relates to enlarged perivisceral fat deposits in the blunt-head cichlid Tropheus moorii. Journal of Evolutionary Biology, 27(10), 2177-2190. doi:10.1111/jeb.12467

Hamilton, W. D., \& Zuk, M. (1982). Heritable true fitness and bright birds: a role for parasites? Science, 218(4570), 384-387. doi:10.1126/science.7123238

Hess, C. M., \& Edwards, S. V. (2002). The evolution of the major histocompatibility complex in birds. Bioscience, 52(5), 423-431. doi:10.1641/0006-3568(2002)052[0423:teotmh]2.0.co;2

Hoover, B., Alcaide, M., Jennings, S., Sin, S. Y. W., Edwards, S. V., \& Nevitt, G. A. (2018). Ecology can inform genetics: Disassortative mating contributes to MHC polymorphism in Leach's stormpetrels (Oceanodroma leucorhoa). Molecular Ecology, 27(16), 3371-3385. doi:10.1111/mec.14801

Huchard, E., Baniel, A., Schliehe-Diecks, S., \& Kappeler, P. M. (2013). MHC-disassortative mate choice and inbreeding avoidance in a solitary primate. Molecular Ecology, 22(15), 4071-4086. doi:10.1111/mec.12349

Huchard, E., Knapp, L. A., Wang, J. L., Raymond, M., \& Cowlishaw, G. (2010). MHC, mate choice and heterozygote advantage in a wild social primate. Molecular Ecology, 19(12), 2545-2561. doi:10.1111/j.1365-294X.2010.04644.x

Jager, I., Eizaguirre, C., Griffiths, S. W., Kalbe, M., Krobbach, C. K., Reusch, T. B. H., . . Milinski, M. (2007). Individual MHC class I and MHC class IIB diversities are associated with male and female reproductive traits in the three-spined stickleback. Journal of Evolutionary Biology, 20(5), 2005-2015. doi:10.1111/j.1420-9101.2007.01366.x

Jodice, P. G. R., Lanctot, R. B., Gill, V. A., Roby, D. D., \& Hatch, S. A. (2000). Sexing adult blacklegged kittiwakes by DNA, behavior, and morphology. Waterbirds, 23(3), 405-415.

Kahm, M., Hasenbrink, G., Lichtenberg-Frate, H., Ludwig, J., \& Kschischo, M. (2010). grofit: fitting biological growth curves with R. Journal of Statistical Software, 33(7), 1-21.

Kalbe, M., Eizaguirre, C., Dankert, I., Reusch, T. B. H., Sommerfeld, R. D., Wegner, K. M., \& Milinski, M. (2009). Lifetime reproductive success is maximized with optimal major histocompatibility complex diversity. Proceedings of the Royal Society B-Biological Sciences, 276(1658), 925-934. doi:10.1098/rspb.2008.1466

Kembel, S. W., Cowan, P. D., Helmus, M. R., Cornwell, W. K., Morlon, H., Ackerly, D. D., . . Webb, C. O. (2010). Picante: R tools for integrating phylogenies and ecology. Bioinformatics, 26(11), 1463-1464. doi:10.1093/bioinformatics/btq166

Klein, S. L., \& Flanagan, K. L. (2016). Sex differences in immune responses. Nature Reviews Immunology, 16(10), 626-638. doi:10.1038/nri.2016.90

Leclaire, S., Strandh, M., Dell'Ariccia, G., Gabirot, M., Westerdahl, H., \& Bonadonna, F. (2019). Plumage microbiota covaries with the major histocompatibility complex in blue petrels. Molecular Ecology, 28(4), 833-846. doi:10.1111/mec.14993

Leclaire, S., van Dongen, W. F. D., Voccia, S., Merkling, T., Ducamp, C., Hatch, S. A., . . Wagner, R. H. (2014). Preen secretions encode information on MHC similarity in certain sex-dyads in a monogamous seabird. Scientific Reports, 4, 6. doi:10.1038/srep06920

Lenz, T. L., Eizaguirre, C., Scharsack, J. P., Kalbe, M., \& Milinski, M. (2009). Disentangling the role of MHC-dependent 'good genes' and 'compatible genes' in mate-choice decisions of threespined sticklebacks Gasterosteus aculeatus under semi-natural conditions. Journal of Fish Biology, 75(8), 2122-2142. doi:10.1111/j.1095-8649.2009.02410.x

Lenz, T. L., Hafer, N., Samonte, I. E., Yeates, S. E., \& Milinski, M. (2018). Cryptic haplotypespecific gamete selection yields offspring with optimal MHC immune genes. Evolution, 72(11), 24782490. doi:10.1111/evo.13591

Lenz, T. L., Mueller, B., Trillmich, F., \& Wolf, J. B. W. (2013). Divergent allele advantage at MHCDRB through direct and maternal genotypic effects and its consequences for allele pool composition and mating. Proceedings of the Royal Society B-Biological Sciences, 280(1762), 9. doi:10.1098/rspb.2013.0714 
Lenz, T. L., Wells, K., Pfeiffer, M., \& Sommer, S. (2009). Diverse MHC IIB allele repertoire increases parasite resistance and body condition in the Long-tailed giant rat (Leopoldamys sabanus). Bmc Evolutionary Biology, 9, 13. doi:10.1186/1471-2148-9-269

Maunder, J. E., \& Threlfall, W. (1972). Breeding biology of black-legged kittiawake in Newfoundland. Auk, 89(4), 789-816.

McClelland, E. E., Penn, D. J., \& Potts, W. K. (2003). Major histocompatibility complex heterozygote superiority during coinfection. Infection and Immunity, 71(4), 2079-2086. doi:10.1128/iai.71.4.2079-2086.2003

McCoy, K. D., Boulinier, T., Schjorring, S., \& Michalakis, Y. (2002). Local adaptation of the ectoparasite Ixodes uriae to its seabird host. Evolutionary Ecology Research, 4(3), 441-456.

Merila, J., \& Sheldon, B. C. (1999). Genetic architecture of fitness and nonfitness traits: empirical patterns and development of ideas. Heredity, 83, 103-109. doi:10.1038/sj.hdy.6885850

Merkling, T., Agdere, L., Albert, E., Durieux, R., Hatch, S. A., Danchin, E., \& Blanchard, P. (2014). Is natural hatching asynchrony optimal? An experimental investigation of sibling competition patterns in a facultatively siblicidal seabird. Behavioral Ecology and Sociobiology, 68(2), 309-319. doi:10.1007/s00265-013-1646-y

Merkling, T., Leclaire, S., Danchin, E., Lhuillier, E., Wagner, R. H., White, J., . . Blanchard, P. (2012). Food availability and offspring sex in a monogamous seabird: insights from an experimental approach. Behavioral Ecology, 23(4), 751-758. doi:10.1093/beheco/ars023

Merkling, T., Perrot, C., Helfenstein, F., Ferdy, J. B., Gaillard, L., Lefol, E., . . Blanchard, P. (2016). Maternal effects as drivers of sibling competition in a parent-offspring conflict context? An experimental test. Ecology and Evolution, 6(11), 3699-3710. doi:10.1002/ece3.1777

Milinski, M. (2006). The major histocompatibility complex, sexual selection, and mate choice. In Annual Review of Ecology Evolution and Systematics (Vol. 37, pp. 159-186). Palo Alto: Annual Reviews.

Minias, P., Pikus, E., Whittingham, L. A., \& Dunn, P. O. (2018). A global analysis of selection at the avian MHC. Evolution, 72(6), 1278-1293. doi:10.1111/evo.13490

Minias, P., Pikus, E., Whittingham, L. A., \& Dunn, P. O. (2019). Evolution of copy number at the MHC varies across the avian tree of life. Genome Biology and Evolution, 11(1), 17-28. doi:10.1093/gbe/evy253

Moller, A. P., Arriero, E., Lobato, E., \& Merino, S. (2009). A meta-analysis of parasite virulence in nestling birds. Biological Reviews, 84(4), 567-588. doi:10.1111/j.1469-185X.2009.00087.x

Murphy, K., \& Weaver, C. (2017). Janeway's immunobiology (9th ed.). New York, NY: Garland Science, Taylor \& Francis Group, LLC.

Nakagawa, S., \& Freckleton, R. P. (2011). Model averaging, missing data and multiple imputation: a case study for behavioural ecology. Behavioral Ecology and Sociobiology, 65(1), 103116. doi:10.1007/s00265-010-1044-7

Navara, K. J. (2018). Choosing Sexes. Switzerland: Springer International Publishing.

Nowak, M. A., Tarczyhornoch, K., \& Austyn, J. M. (1992). The optimal number of major histocompatibility complex molecules in an individual. Proceedings of the National Academy of Sciences of the United States of America, 89(22), 10896-10899. doi:10.1073/pnas.89.22.10896

Ober, C., Hyslop, T., Elias, S., Weitkamp, L. R., \& Hauck, W. W. (1998). Human leukocyte antigen matching and fetal loss: results of a 10 year prospective study. Human Reproduction, 13(1), 33-38. doi:10.1093/humrep/13.1.33

Oliver, M. K., Telfer, S., \& Piertney, S. B. (2009). Major histocompatibility complex (MHC) heterozygote superiority to natural multi-parasite infections in the water vole (Arvicola terrestris). Proceedings of the Royal Society B-Biological Sciences, 276(1659), 1119-1128. doi:10.1098/rspb.2008.1525

Owen, J. P., Nelson, A. C., \& Clayton, D. H. (2010). Ecological immunology of bird-ectoparasite systems. Trends in Parasitology, 26(11), 530-539. doi:10.1016/j.pt.2010.06.005 
Pierini, F., \& Lenz, T. L. (2018). Divergent allele advantage at Human MHC genes: signatures of past and ongoing selection. Molecular Biology and Evolution, 35(9), 2145-2158. doi:10.1093/molbev/msy116

Pineaux, M., Blanchard, P., Danchin, E., Hatch A, S., Helfenstein, F., Mulard, H., . . Wagner H, R. (2019). Behavioural avoidance of sperm ageing depends on genetic similarity of mates in a monogamous seabird. Biological Journal of the Linnean Society, 128(1), 170-180. doi:doi:10.0193/biolinnean/blz079

R Core Team. (2018). R: A language and environment for statistical computing. Vienna, Austria: R Foundation for Statistical Computing.

Radwan, J., Zagalska-Neubauer, M., Cichon, M., Sendecka, J., Kulma, K., Gustafsson, L., \& Babik, W. (2012). MHC diversity, malaria and lifetime reproductive success in collared flycatchers. Molecular Ecology, 21(10), 2469-2479. doi:10.1111/j.1365-294X.2012.05547.x

Revell, L. J., \& Chamberlain, S. A. (2014). Rphylip: an R interface for PHYLIP. Methods in Ecology and Evolution, 5(9), 976-981. doi:10.1111/2041-210x.12233

Richards, S. A. (2005). Testing ecological theory using the information-theoretic approach: Examples and cautionary results. Ecology, 86(10), 2805-2814. doi:10.1890/05-0074

Rioux-Paquette, E., Festa-Bianchet, M., \& Coltman, D. W. (2011). Sex-differential effects of inbreeding on overwinter survival, birth date and mass of bighorn lambs. Journal of Evolutionary Biology, 24(1), 121-131. doi:10.1111/j.1420-9101.2010.02154.x

Roved, J. (2019). MHC polymorphism in a songbird: Fitness, mate choice, and sexual conflict. $(\mathrm{PhD})$. Lunds universitet, Lund.

Roved, J., Hansson, B., Tarka, M., Hasselquist, D., \& Westerdahl, H. (2018). Evidence for sexual conflict over major histocompatibility complex diversity in a wild songbird. Proceedings of the Royal Society B-Biological Sciences, 285(1884), 9. doi:10.1098/rspb.2018.0841

Roved, J., Westerdahl, H., \& Hasselquist, D. (2017). Sex differences in immune responses: Hormonal effects, antagonistic selection, and evolutionary consequences. Hormones and Behavior, 88, 95-105. doi:10.1016/j.yhbeh.2016.11.017

Sandberg, M., Eriksson, L., Jonsson, J., Sjostrom, M., \& Wold, S. (1998). New chemical descriptors relevant for the design of biologically active peptides. A multivariate characterization of 87 amino acids. Journal of Medicinal Chemistry, 41(14), 2481-2491. doi:10.1021/jm9700575

Saper, M. A., Bjorkman, P. J., \& Wiley, D. C. (1991). Refined structure of the human histocompatibility antigen HLA-A2 at 2.6 A resolution. Journal of Molecular Biology, 219(2), 277-319. doi:10.1016/0022-2836(91)90567-p

Sauermann, U., Nurnberg, P., Bercovitch, F. B., Berard, J. D., Trefilov, A., Widdig, A., . . Krawczak, M. (2001). Increased reproductive success of MHC class II heterozygous males among freeranging rhesus macaques. Human Genetics, 108(3), 249-254. doi:10.1007/s004390100485

Schaschl, H., Suchentrunk, F., Morris, D. L., Ben Slimen, H., Smith, S., \& Arnold, W. (2012). Sexspecific selection for MHC variability in Alpine chamois. Bmc Evolutionary Biology, 12, 10. doi:10.1186/1471-2148-12-20

Schwensow, N., Eberle, M., \& Sommer, S. (2010). Are there ubiquitous parasite-driven major histocompatibility complex selection mechanisms in gray mouse lemurs? International Journal of Primatology, 31, 519-537. doi:10.1007/s10764-010-9411-9

Schwensow, N., Fietz, J., Dausmann, K. H., \& Sommer, S. (2007). Neutral versus adaptive genetic variation in parasite resistance: importance of major histocompatibility complex supertypes in a free-ranging primate. Heredity, 99, 265-277. doi:https://doi.org/10.1038/sj.hdy.6800993

Sebastian, A., Herdegen, M., Migalska, M., \& Radwan, J. (2016). amplisas: a web server for multilocus genotyping using next-generation amplicon sequencing data. Molecular Ecology Resources, 16(2), 498-510. doi:10.1111/1755-0998.12453 
Sepil, I., Lachish, S., Hinks, A. E., \& Sheldon, B. C. (2013). Mhc supertypes confer both qualitative and quantitative resistance to avian malaria infections in a wild bird population. Proceedings of the Royal Society B-Biological Sciences, 280(1759), 8. doi:10.1098/rspb.2013.0134

Sepil, I., Lachish, S., \& Sheldon, B. C. (2013). Mhc-linked survival and lifetime reproductive success in a wild population of great tits. Molecular Ecology, 22(2), 384-396. doi:10.1111/mec.12123

Setchell, J. M., Abbott, K. M., Gonzalez, J. P., \& Knapp, L. A. (2013). Testing for post-copulatory selection for major histocompatibility complex genotype in a semi-free-ranging primate population. American Journal of Primatology, 75(10), 1021-1031. doi:10.1002/ajp.22166

Smyth, K. N., Caruso, N. M., Davies, C. S., Clutton-Brock, T. H., \& Drea, C. M. (2018). Social and endocrine correlates of immune function in meerkats: implications for the immunocompetence handicap hypothesis. Royal Society Open Science, 5(8), 13. doi:10.1098/rsos.180435

Sommer, S. (2005). The importance of immune gene variability (MHC) in evolutionary ecology and conservation. Frontiers in Zoology, 2(16). doi:https://doi.org/10.1186/1742-9994-2-16

Strandh, M., Westerdahl, H., Pontarp, M., Canback, B., Dubois, M. P., Miquel, C., .. . Bonadonna, F. (2012). Major histocompatibility complex class II compatibility, but not class I, predicts mate choice in a bird with highly developed olfaction. Proceedings of the Royal Society B-Biological Sciences, 279(1746), 4457-4463. doi:10.1098/rspb.2012.1562

Therneau, T. M. (2018). coxme: Mixed Effects Cox Models. R package version 2.2-10. Retrieved from https://CRAN.R-project.org/package=coxme

Thoss, M., Ilmonen, P., Musolf, K., \& Penn, D. J. (2011). Major histocompatibility complex heterozygosity enhances reproductive success. Molecular Ecology, 20(7), 1546-1557. doi:10.1111/j.1365-294X.2011.05009.x

Van Dongen, W. F. D., White, J., Brandl, H. B., Leclaire, S., Hatch, S. A., Danchin, E., \& Wagner, R. H. (2019). Experimental evidence of a sexually transmitted infection in a wild vertebrate, the blacklegged kittiwake (Rissa tridactyla). Biological Journal of the Linnean Society, 127(2), 292-298. doi:10.1093/biolinnean/blz009

Vincenzi, S., Hatch, S., Mangel, M., \& Kitaysky, A. (2013). Food availability affects onset of reproduction in a long-lived seabird. Proceedings of the Royal Society B-Biological Sciences, 280(1760), 9. doi:10.1098/rspb.2013.0554

Vincenzi, S., Hatch, S., Merkling, T., \& Kitaysky, A. S. (2015). Carry-over effects of food supplementation on recruitment and breeding performance of long-lived seabirds. Proceedings of the Royal Society B-Biological Sciences, 282(1812), 191-198. doi:10.1098/rspb.2015.0762

Wakeland, E. K., Boehme, S., She, J. X., Lu, C. C., McIndoe, R. A., Cheng, I., . . Potts, W. K. (1990). Ancestral polymorphisms of MHC class-II genes: divergent allele advantage. Immunologic Research, 9(2), 115-122. doi:10.1007/bf02918202

Wedekind, C., Chapuisat, M., Macas, E., \& Rulicke, T. (1996). Non-random fertilization in mice correlates with the MHC and something else. Heredity, 77, 400-409. doi:10.1038/hdy.1996.160

Wegner, K. M., Reusch, T. B. H., \& Kalbe, M. (2003). Multiple parasites are driving major histocompatibility complex polymorphism in the wild. Journal of Evolutionary Biology, 16(2), 224232. doi:10.1046/j.1420-9101.2003.00519.x

White, J., Leclaire, S., Kriloff, M., Mulard, H., Hatch, S. A., \& Danchin, E. (2010). Sustained increase in food supplies reduces broodmate aggression in black-legged kittiwakes. Animal Behaviour, 79(5), 1095-1100. doi:10.1016/j.anbehav.2010.02.003

White, J., Mirleau, P., Danchin, E., Mulard, H., Hatch, S. A., Heeb, P., \& Wagner, R. H. (2010). Sexually transmitted bacteria affect female cloacal assemblages in a wild bird. Ecology Letters, 13(12), 1515-1524. doi:10.1111/j.1461-0248.2010.01542.x

Whittingham, L. A., Dunn, P. O., Freeman-Gallant, C. R., Taff, C. C., \& Johnson, J. A. (2018). Major histocompatibility complex variation and blood parasites in resident and migratory populations of the common yellowthroat. Journal of Evolutionary Biology, 31(10), 1544-1557. doi:10.1111/jeb.13349 
Willink, B., \& Svensson, E. I. (2017). Intra- and intersexual differences in parasite resistance and female fitness tolerance in a polymorphic insect. Proceedings of the Royal Society B-Biological Sciences, 284(1847), 8. doi:10.1098/rspb.2016.2407

Winternitz, J. C., Minchey, S. G., Garamszegi, L. Z., Huang, S., Stephens, P. R., \& Altizer, S. (2013). Sexual selection explains more functional variation in the mammalian major histocompatibility complex than parasitism. Proceedings of the Royal Society B-Biological Sciences, 280(1769), 8. doi:10.1098/rspb.2013.1605

Woelfing, B., Traulsen, A., Milinski, M., \& Boehm, T. (2009). Does intra-individual major histocompatibility complex diversity keep a golden mean? Philosophical Transactions of the Royal Society B-Biological Sciences, 364(1513), 117-128. doi:10.1098/rstb.2008.0174

Zhu, Y., Wan, Q. H., Zhang, H. M., \& Fang, S. G. (2019). Reproductive strategy inferred from major histocompatibility complex-based inter-individual, sperm-egg, and mother-fetus recognitions in giant pandas (Ailuropoda melanoleuca). Cells, 8(3), 21. doi:10.3390/cells8030257

Zuk, M., \& Stoehr, A. M. (2002). Immune defense and host life history. American Naturalist, 160, S9-S22. doi:10.1086/342131

Zuur, A. F., leno, E. N., \& Elphick, C. S. (2010). A protocol for data exploration to avoid common statistical problems. Methods in Ecology and Evolution, 1(1), 3-14. doi:10.1111/j.2041210X.2009.00001.x

\section{DATA ACCESSIBILITY}

Data are available on Open Science Framework. Pineaux, M., et al. (2020). MHC-II fitness associations in kittiwakes. Open Science Framework. doi:10.17605/OSF.IO/DN5Y8.

(https://osf.io/dn5y8/?view only=97ddd8f65a264c62bd540b1e4e9148a5).

\section{AUTHOR CONTRIBUTIONS}

$\mathrm{MP}, \mathrm{PB}$ and SL conceived and designed the study. ED, MP, PB, SL and TM collected the data. MP, SL and TM carried out the molecular analyses. SAH is responsible of the long-term monitoring on Middleton Island and gave access to the study area. MP and TM performed the statistical analyses. MP wrote the manuscript and all authors contributed comments. All authors gave final approval for publication. 

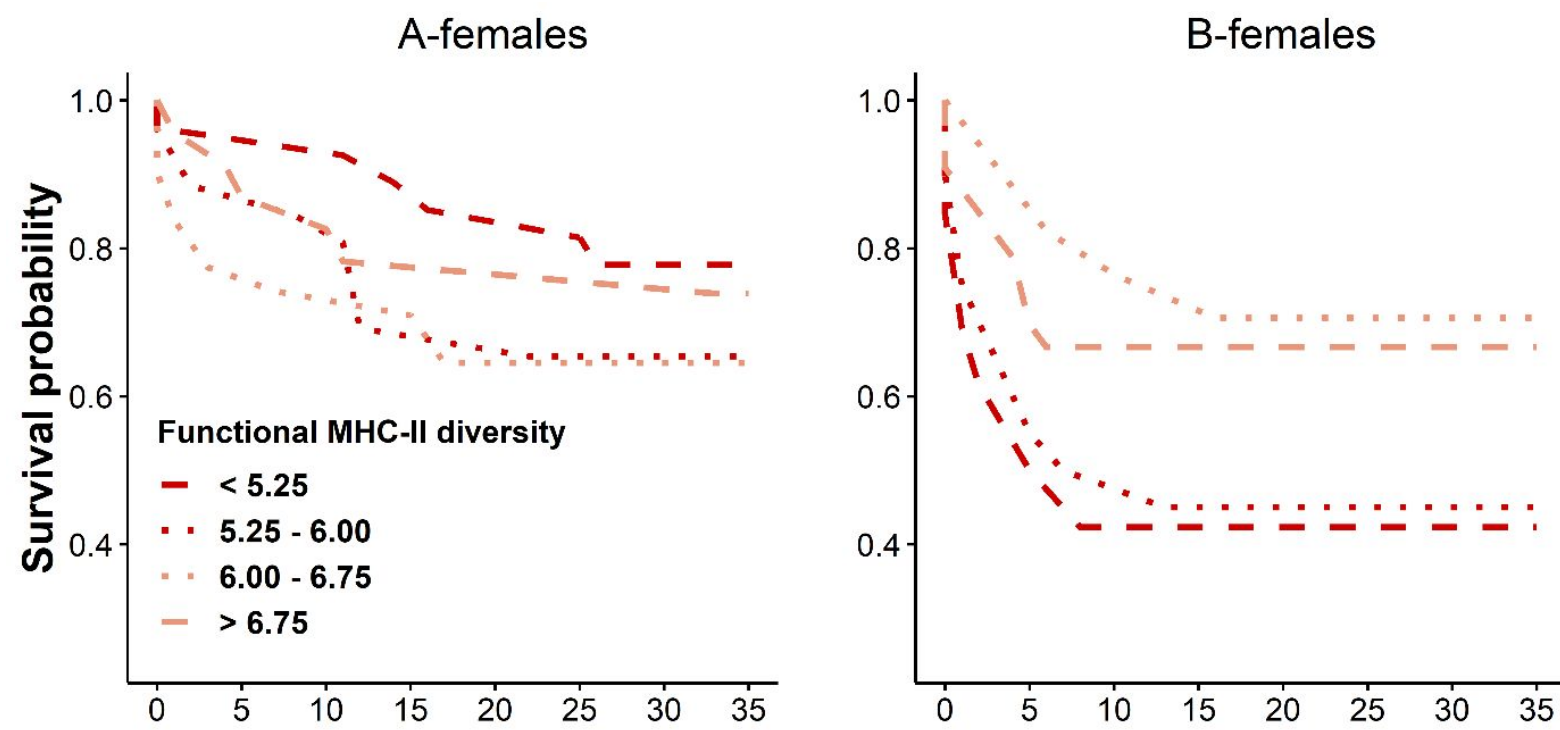

A-males
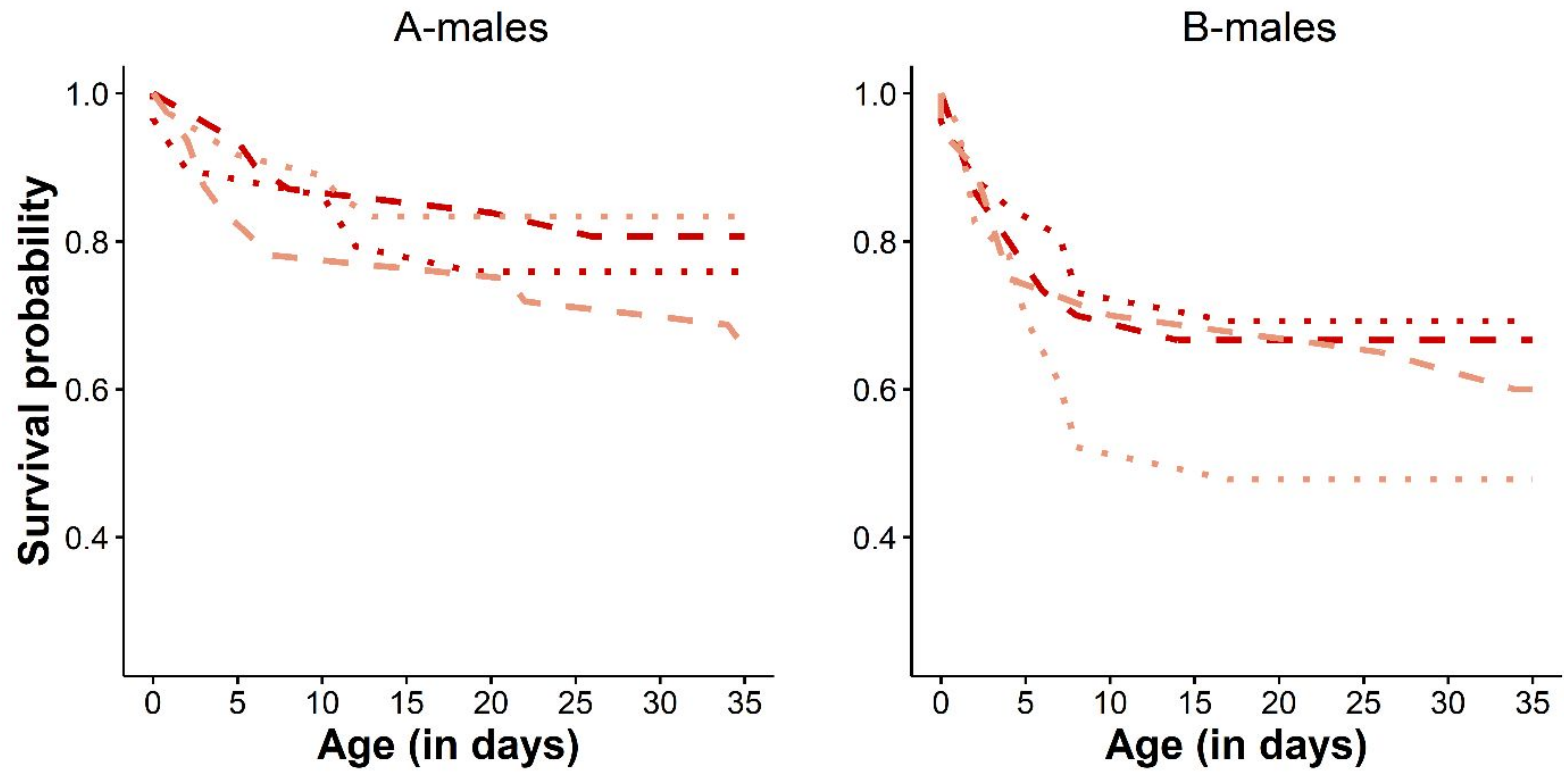

Figure 1. Chick survival probability during the nestling stage according to functional MHC-II diversity for female A- $(n=107)$, female B- $(n=96)$, male A- $(n=128)$ and male B-chicks $(n=99)$. Although functional MHC-II diversity was analyzed as a continuous variable (see text), it is displayed here as a categorical variable for illustrative purposes. We categorized MHC-II diversity in four groups using quartiles of the whole data set used for survival analyses $(n=430)$. The colors and line types represent MHC-II diversity, with red corresponding to the first (dashed line) and second (dotted line) quartiles (i.e. low MHC-II diversity) and pink to the third (dotted line) and fourth (dashed line) quartiles (i.e. high MHC-II diversity). See supporting information (Figure S10) for a different display (heatmap). 


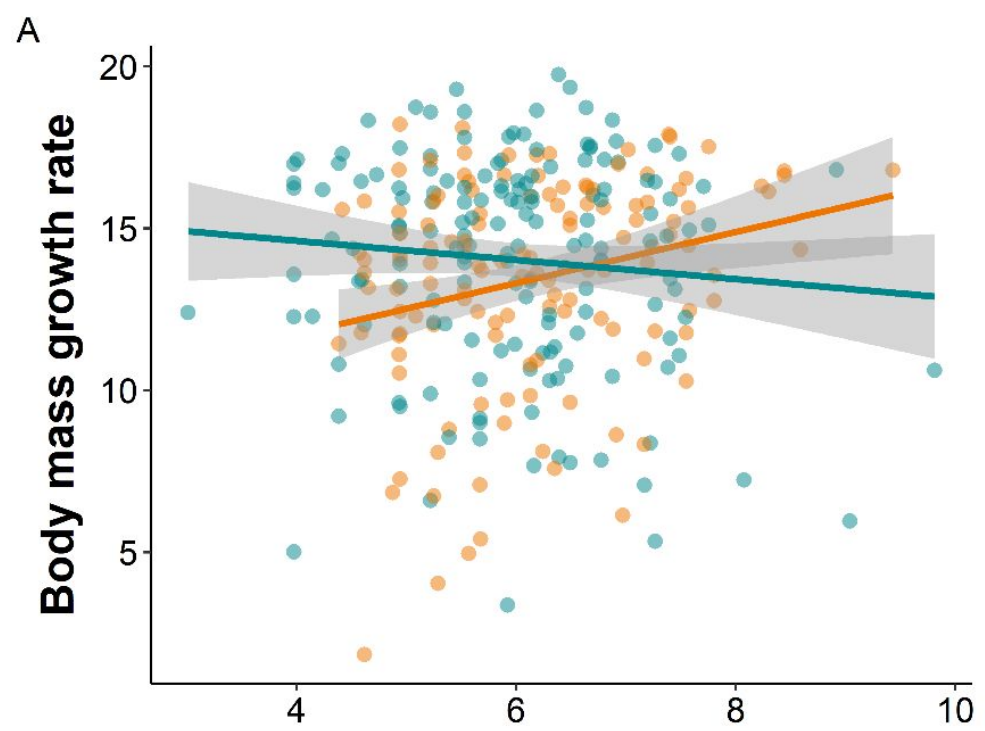

B

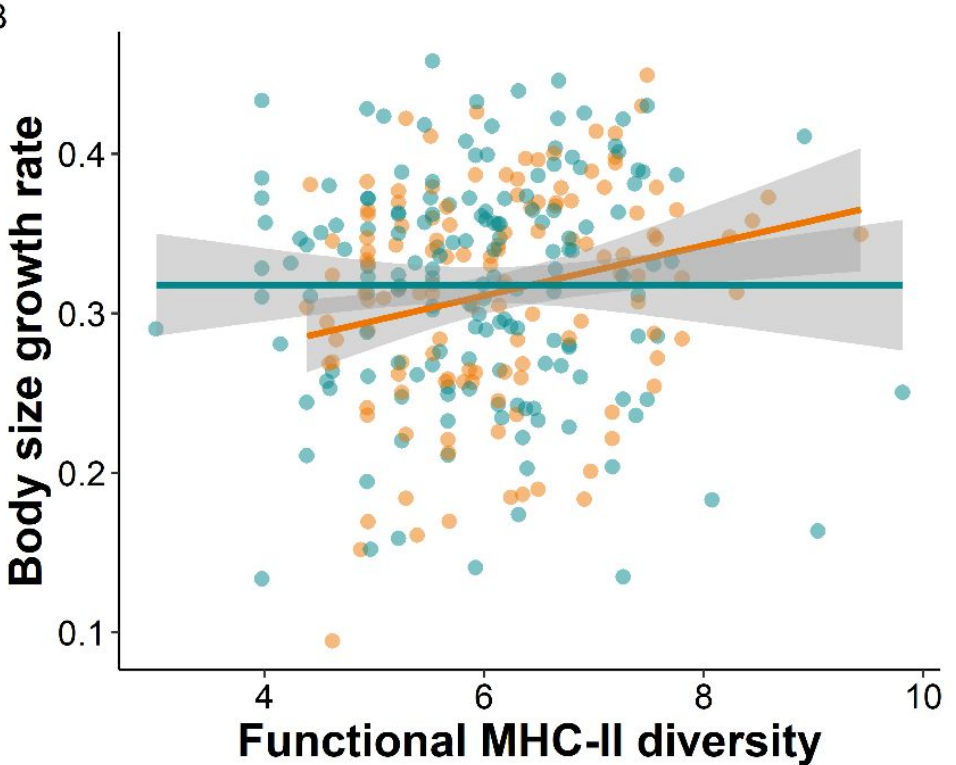

Figure 2. Growth rate of $(A)$ chick body mass and $(B)$ chick body size over the first 10 days according to functional MHC-II diversity in females ( $n=131$, in orange) and males ( $n=160$, in blue). Chick size was estimated by taking the scores of the first principal component analysis on wing and tarsus length. Growth rate was calculated as the slope of a linear regression between morphological measures and age (see methods for more details). One male with a very low MHC-Il diversity (i.e. 0.88) has been removed to improve clarity of the figure (see Figure S12 for a figure including this male). Removing this male from analyses did not change the results. Regression lines were derived from single-sex models including functional MHC-II diversity of chicks as a fixed effect. Random effects (year and clutch ID) were not considered in the models used for graphic representations. Shaded areas represent 

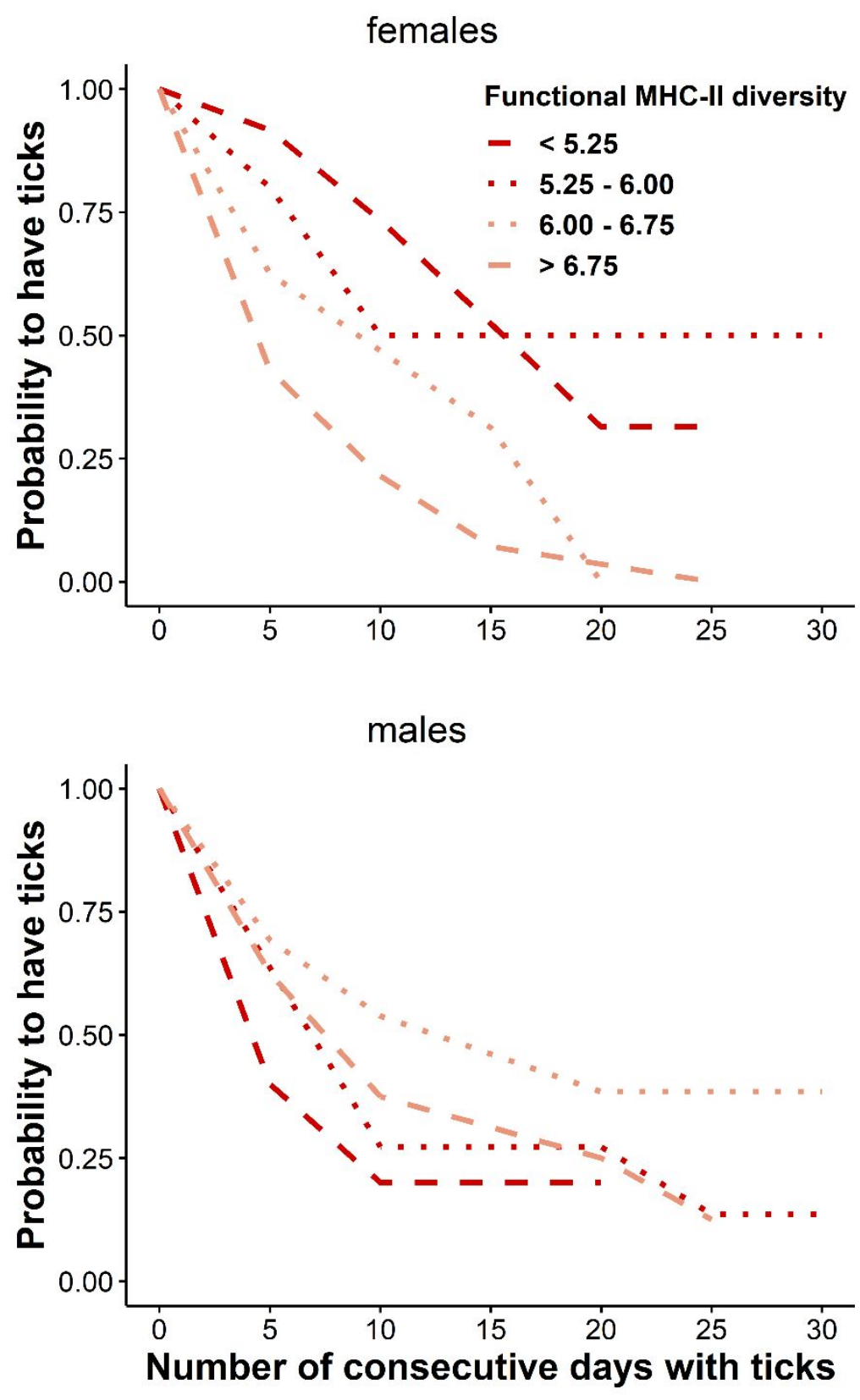

Figure 3. Probability of chicks to be infected according to infection duration and functional MHC-II diversity for females $(n=44)$ and males $(n=42)$. Although functional MHC-II diversity was analyzed as a continuous variable (see text), it is displayed here as a categorical variable for illustrative purposes. We categorized MHC-II diversity in four groups using quartiles of the whole data set used for tick analyses $(n=86)$. The colors and line types represent MHC-II diversity, with red corresponding to the first (dashed line) and second (dotted line) quartiles (i.e. low MHC-II diversity) and pink to the third (dotted line) and fourth (dashed line) quartiles (i.e. high MHC-II diversity). 


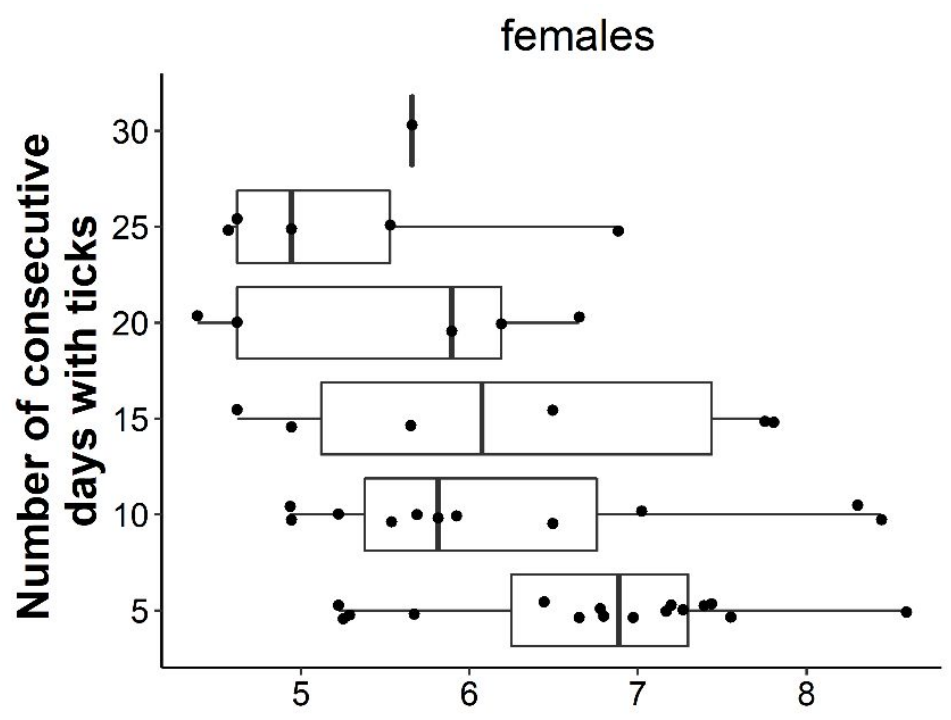

males

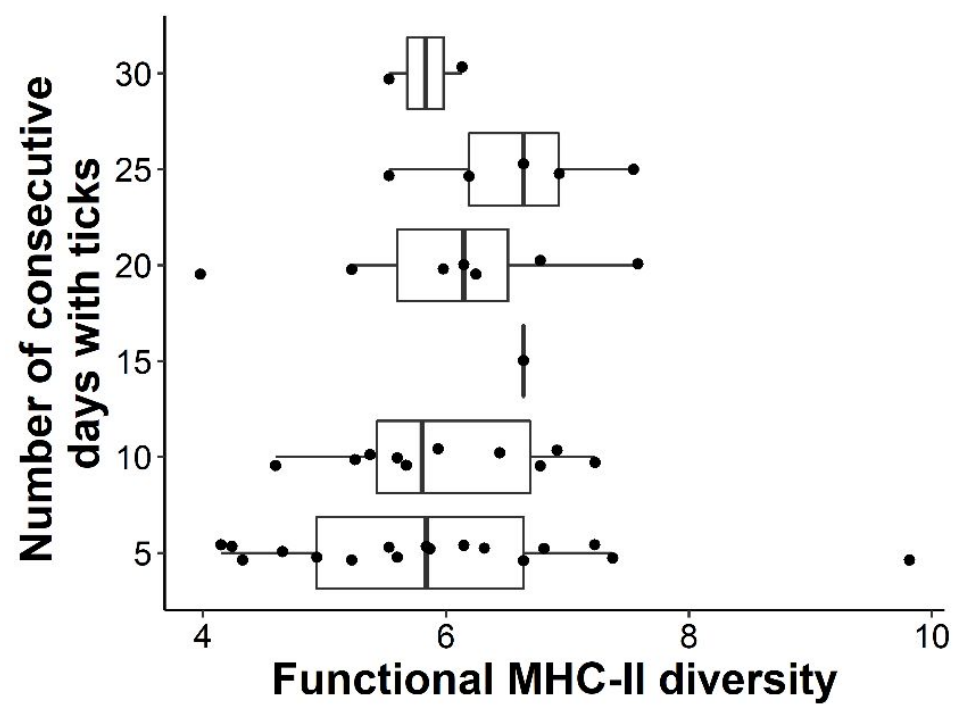

Figure 4. Boxplots of functional MHC-II diversity according to the number of consecutive days chicks were observed with ticks for females $(n=44)$ and males $(n=42)$. 

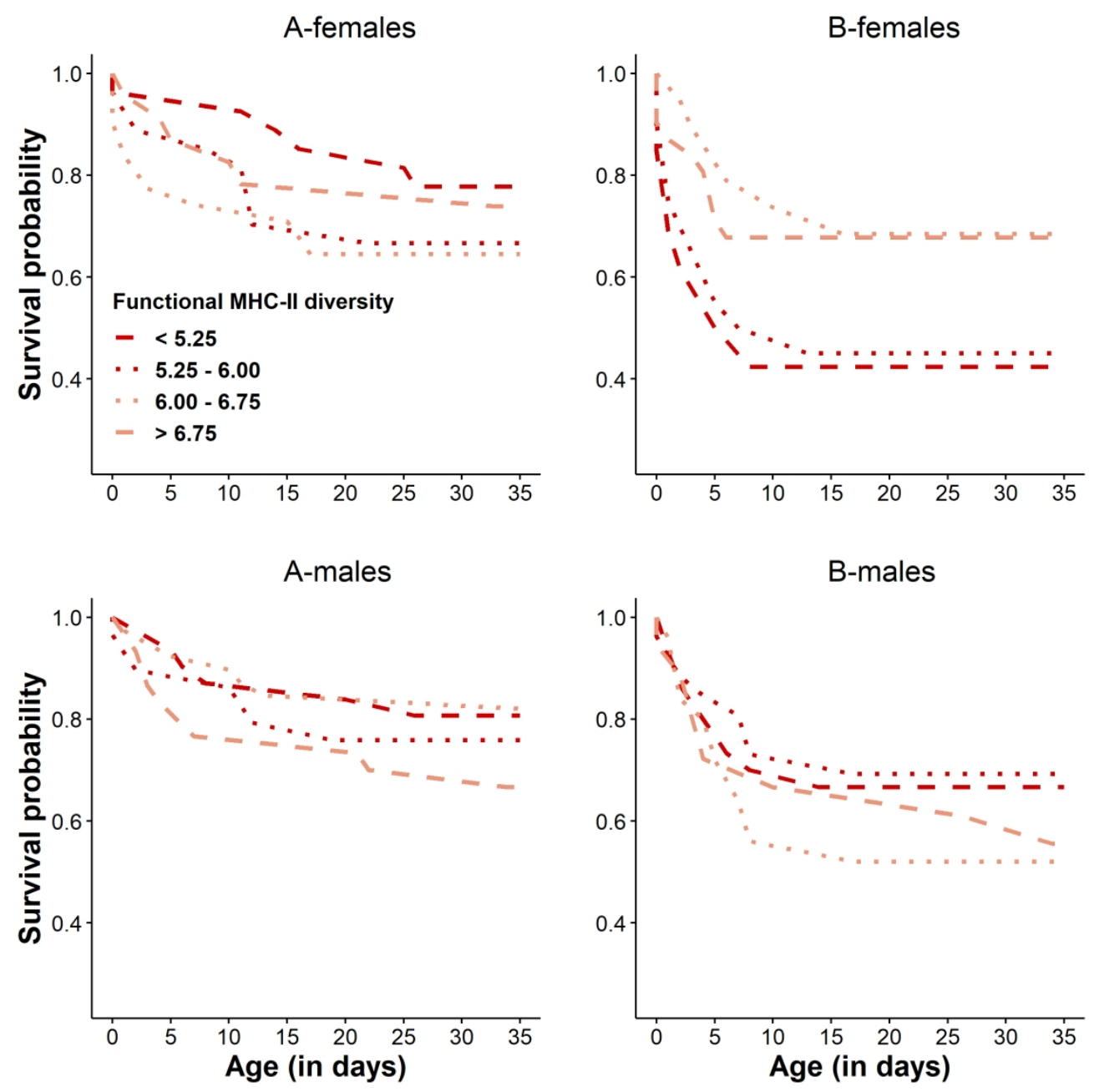

$209 \times 209 \mathrm{~mm}(300 \times 300 \mathrm{DPI})$ 

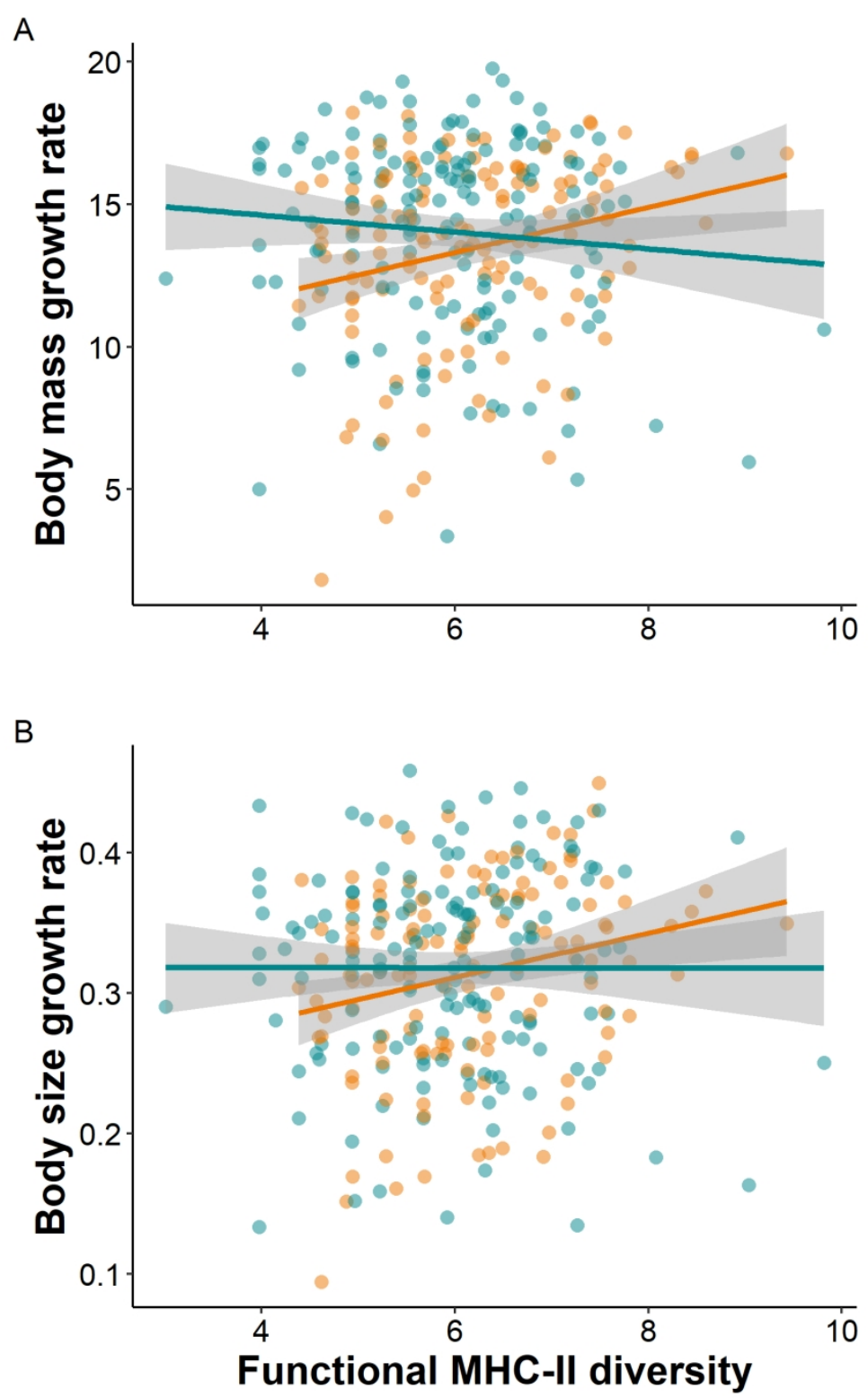

$129 \times 209 m m(300 \times 300$ DPI $)$ 

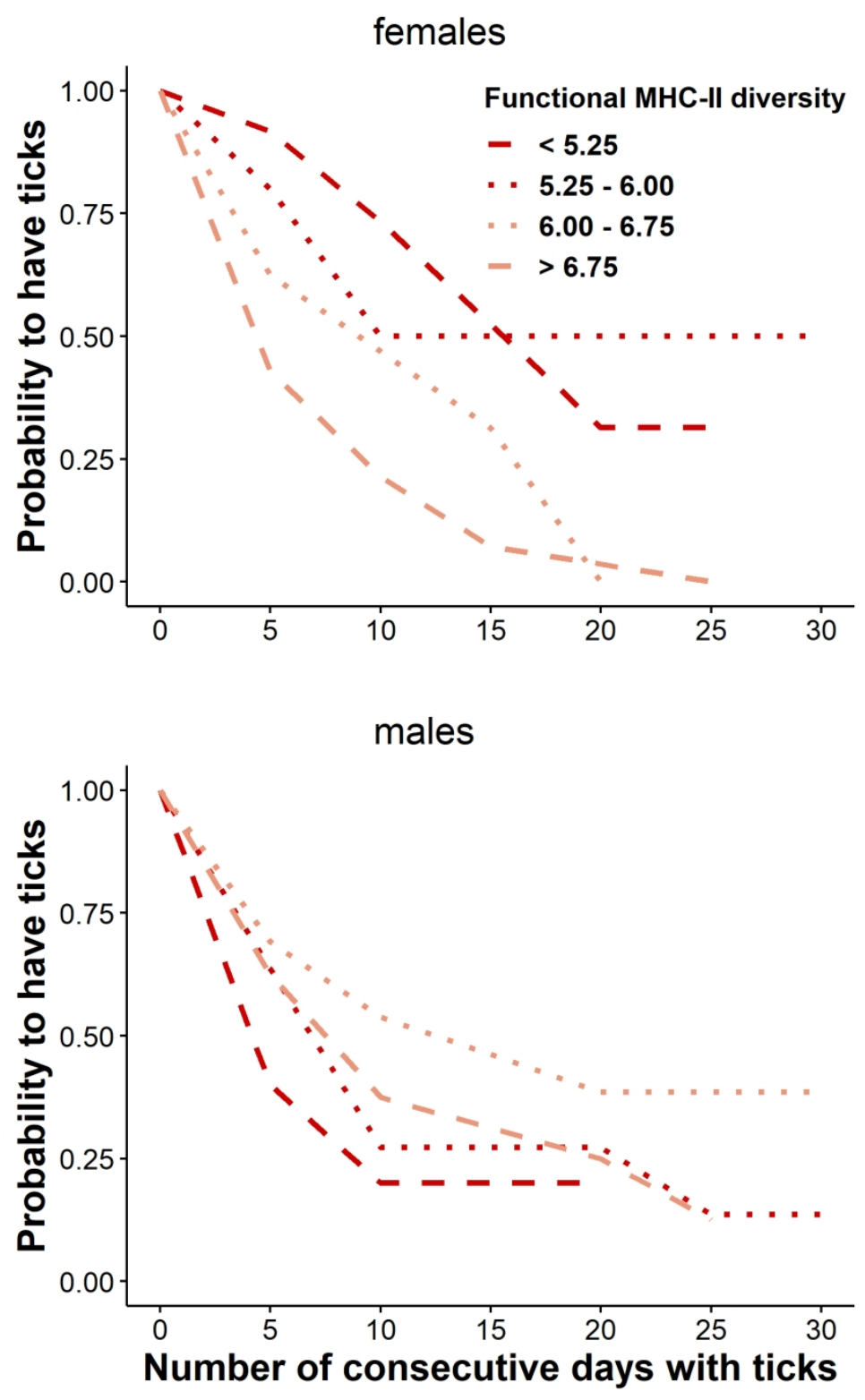

$129 \times 209 \mathrm{~mm}(300 \times 300$ DPI $)$ 

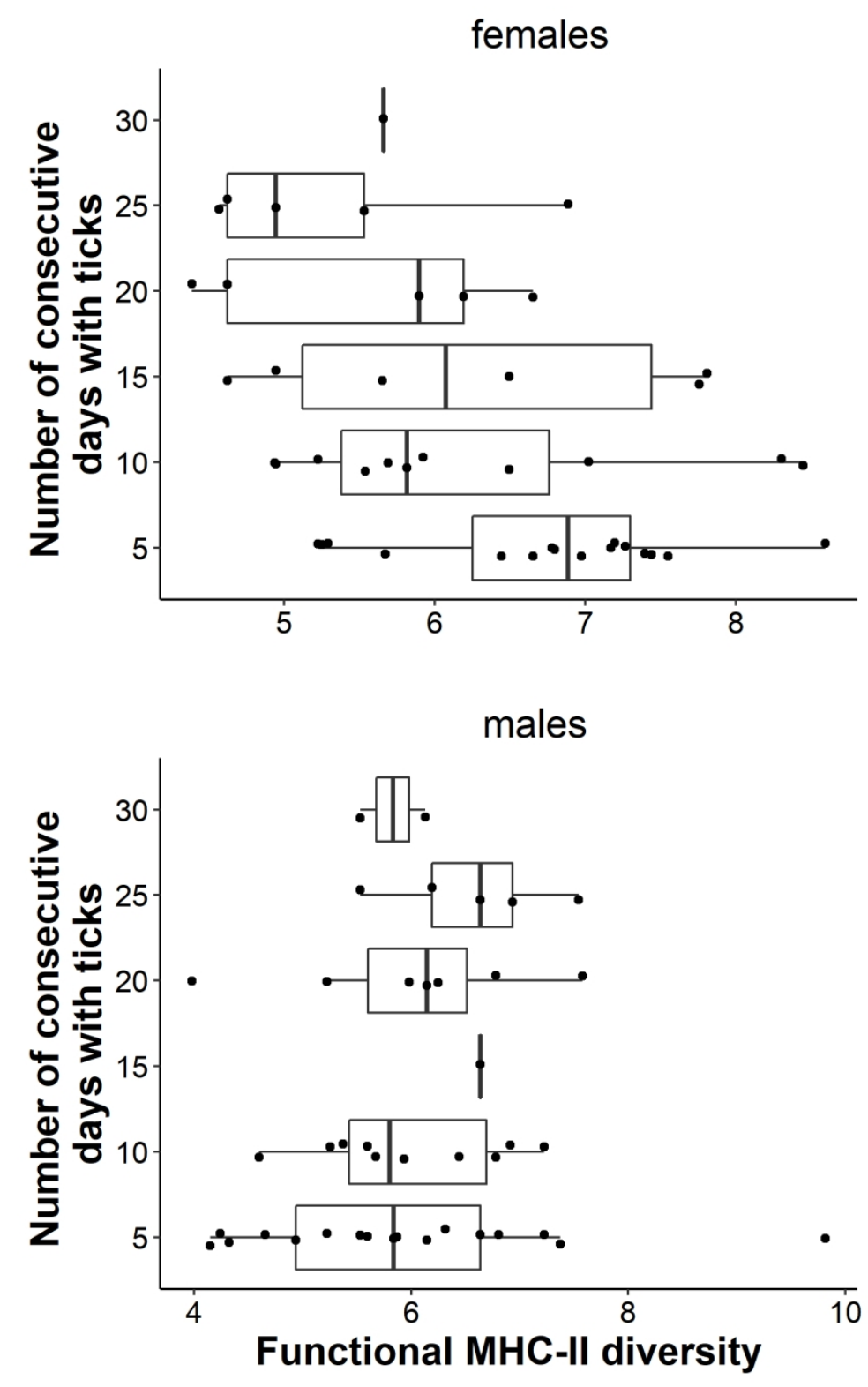

$129 \times 209 \mathrm{~mm}(300 \times 300 \mathrm{DPI})$ 